第 第 第第第節節章節第第第第

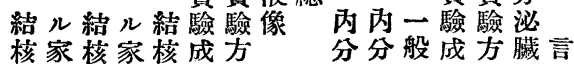
菌鬼菌鬼菌績法括泌泌桀績法器 毒〉瑇〉毒 素血潔血素 キ夜 キ夜 キ 直像連像一 接續 回 早皮皮 腺 $=$ 腺 注、注 作 射射 用 七 哭哭單藏態組 少告 組重體 織量重 的學戀絔 椞 化

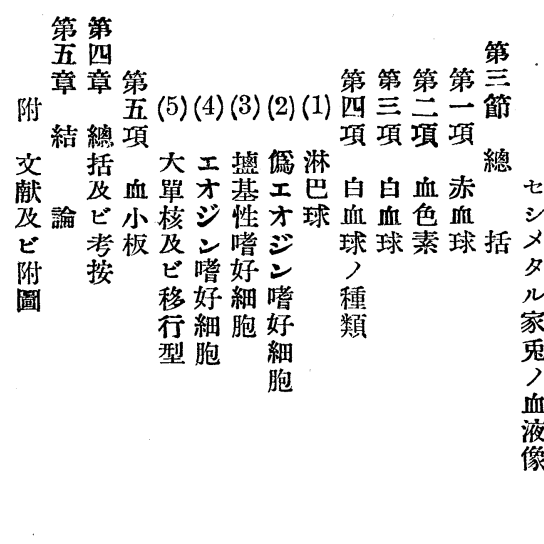

目

兔 結

八核

内 菌

分毒

泌 素

臟 チ

器 直

人接

組 甲

織 狀

學 腺

次

郎 


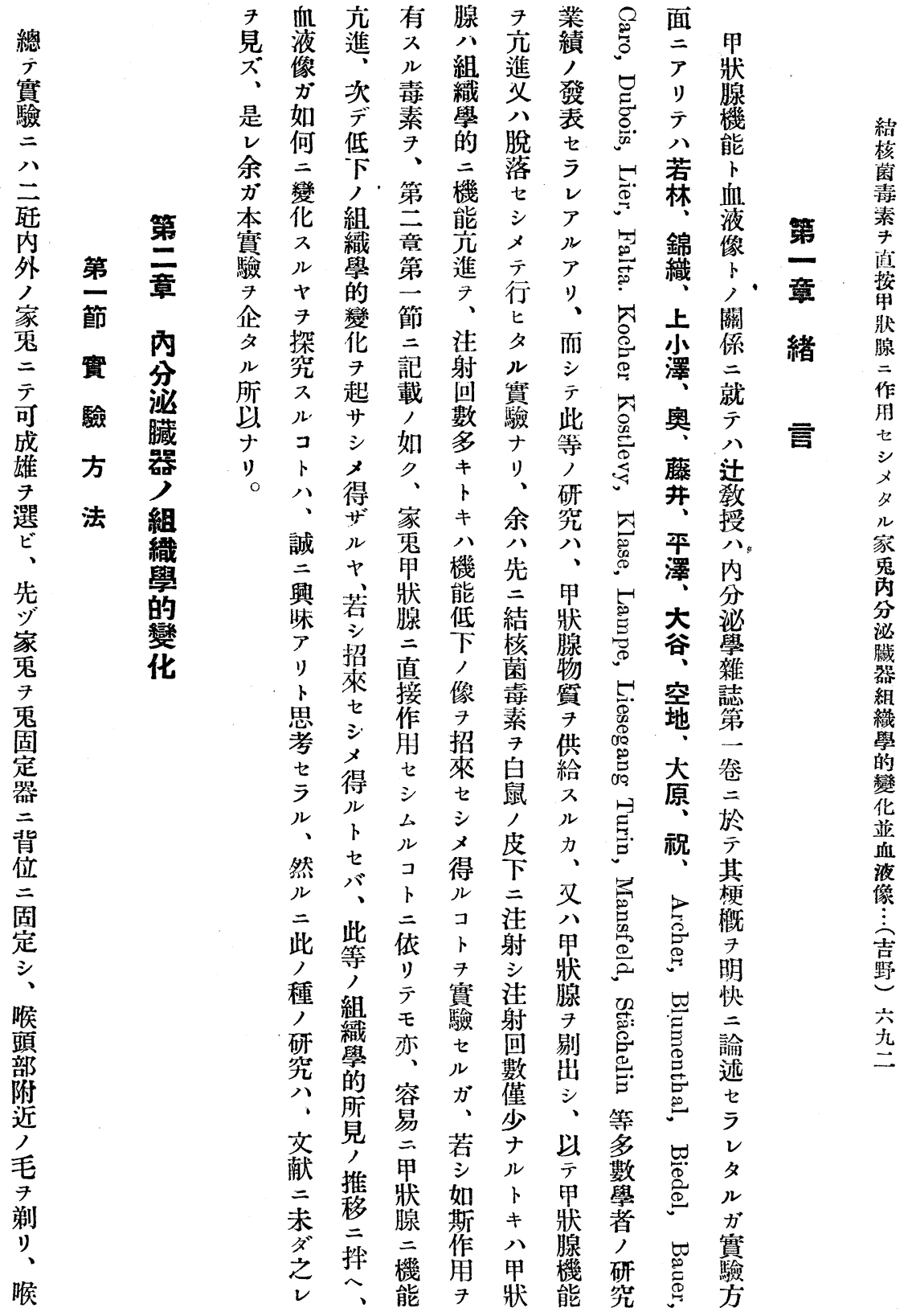




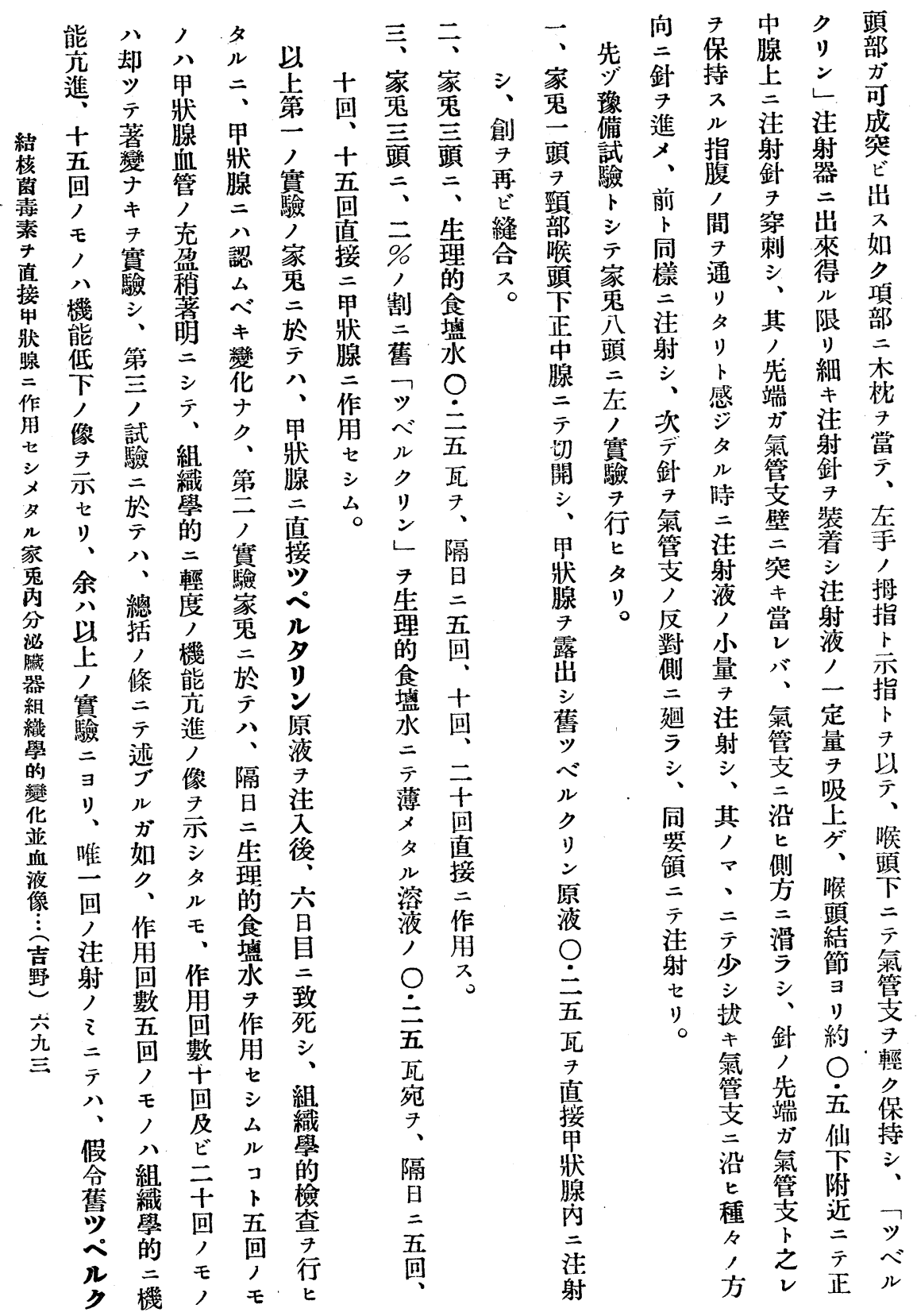




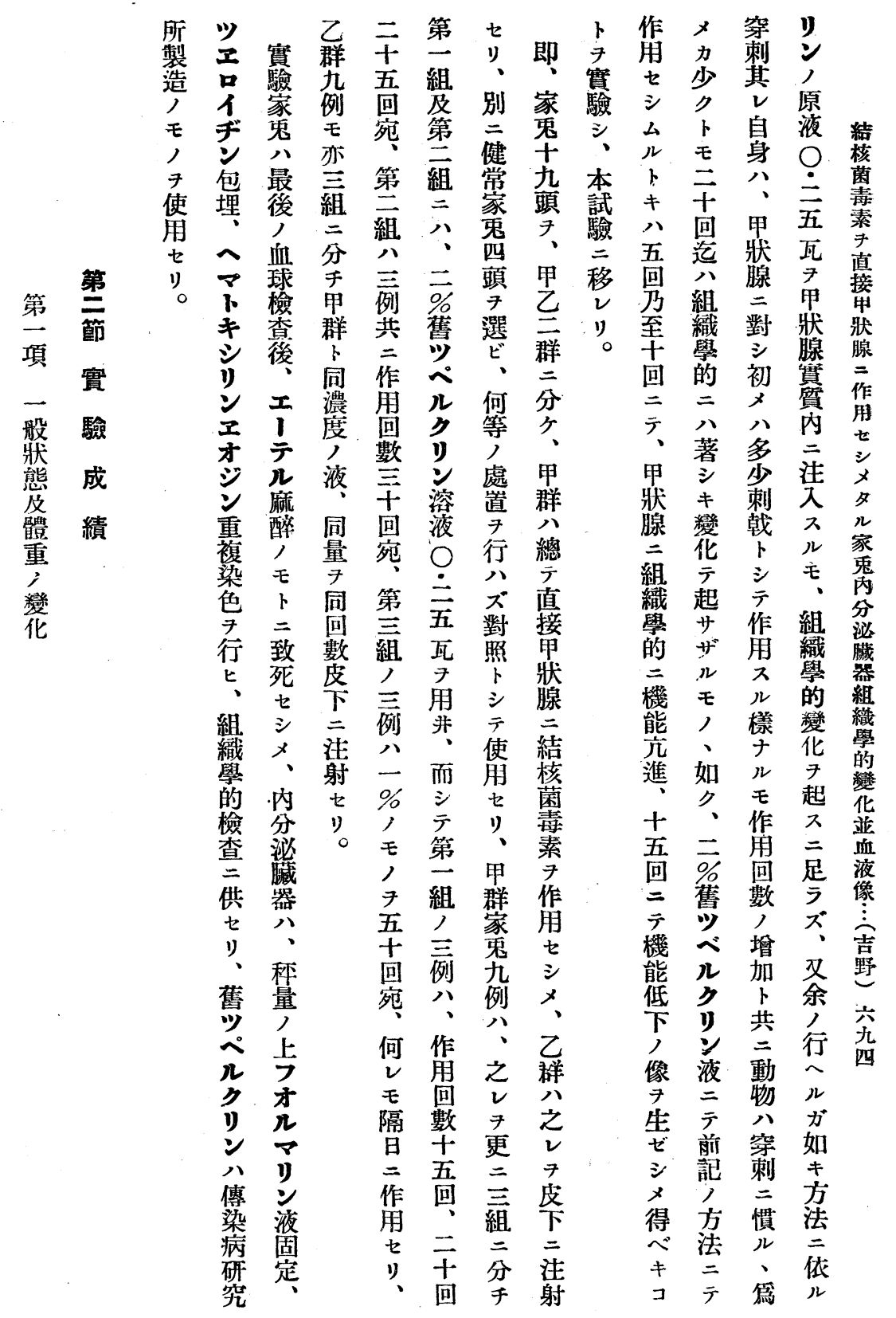


第一表ノ一 甲群家鬼體重表 (單位瓦)

\begin{tabular}{|c|c|c|c|c|c|c|c|c|c|c|c|c|c|c|}
\hline \multirow{2}{*}{$\begin{array}{l}\text { 動 } \\
\text { 物 } \\
\text { 番 } \\
\text { 號 } \\
\end{array}$} & \multirow{2}{*}{ 性 } & \multirow{2}{*}{$\mid$\begin{tabular}{|l|} 
試體 \\
驗 \\
前重
\end{tabular}} & \multicolumn{3}{|r|}{ 試 } & \multicolumn{2}{|l|}{ 驗 } & \multicolumn{2}{|c|}{ 體 } & \multicolumn{3}{|l|}{ 重 } & \multirow{2}{*}{$\begin{array}{l}\text { 㙁 } \\
\text { 加 }\end{array}$} & \multirow{2}{*}{$\begin{array}{l}\text { 减 } \\
\text { 少 }\end{array}$} \\
\hline & & & 10日 & 20日 & 30 日 & 40 日 & 50 日 & 60 日 & 70 日 & 80 日 & 90 日 & 100 日 & & \\
\hline 1 & & $2.540 \mid$ & 2.625 & & & & & & & & & & 85 & \\
\hline 2 & + & 2.250 & 2.200 & 2.100 & & & & & & & & & & 150 \\
\hline 3 & q & 2.025 & 1.827 & 1.850 & 1.850 & & & & & & & & & 175 \\
\hline 4 & $\hat{\jmath}$ & 1.920 & 1.875 & 1.762 & 1.772 & & & & & & & & & 148 \\
\hline 5 & ㅇ & 2.400 & 2.438 & 2.550 & 2.580 & 2.738 & & & & & & & 338 & \\
\hline 6 & $\uparrow$ & 2.250 & 2.150 & 2.200 & 2.260 & 2.250 & 2.300 & & & & & & 50 & \\
\hline 7 & $\hat{\delta}$ & 2.250 & 2.220 & 2.050 & 2.050 & 2.200 & 2.350 & 2.250 & & & & & & \\
\hline 8 & $q$ & 2.270 & 1.950 & 1.850 & 1.970 & 2.250 & 2.320 & 2.450 & & & & & 180 & \\
\hline 9 & $\hat{\jmath}$ & 1.550 & 1.420 & 1.300 & 1.560 & 1.670 & 1.650 & 1.650 & & & & & 100 & \\
\hline 10 & $\hat{\sigma}$ & 2.400 & 2.400 & 2.050 & 2.017 & 2.600 & 2.500 & 2.500 & 2.500 & 2.500 & 2.700 & 2.720 & 320 & \\
\hline 11 & $\hat{\delta}$ & 2.450 & 2.270 & 2.350 & 2.250 & 2.540 & 2.540 & 2.700 & 2.850 & 3.000 & 2.700 & 2.500 & 50 & \\
\hline 12 & $\uparrow$ & 2.250 & 2.250 & 2.320 & 2.280 & 2.350 & 2.290 & 2.320 & 2.320 & 2.320 & 2.320 & 2.300 & 50 & \\
\hline 體 & 减 & 少 & 8例 & 6例 & 3 例 & 2例 & 3例 & 1例 & 0 & 0 & 1例 & 2例 & & \\
\hline & & 加 & $2 \prime \prime$ & $5 / 1$ & $5 / 1$ & $7 / 1$ & $3 / \prime$ & $3 / 1$ & 1例 & 1例 & $1 / 1$ & $1 / /$ & & \\
\hline 重 & 變化 & ヒナシ & $2 \prime \prime$ & 0 & $2 \prime \prime$ & 0 & $1 / /$ & $2 /$ & $2 / 1$ & $2 \prime \prime$ & $1 / 1$ & 0 & & \\
\hline & & & & 第一 & 表ノニ & 二 乙群 & 群家鬼 & 體重表 & 垡 $\{$ 單 & 位瓦） & & & & \\
\hline $\begin{array}{l}\text { 動 } \\
\text { 物 }\end{array}$ & 性 & 試體 & & & 試 & 驗 & 後 & 酸 & 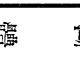 & 重 & & & 增 & 减 \\
\hline $\begin{array}{l}\text { 番 } \\
\text { 號 } \\
\end{array}$ & & 前重 & 10日 & 20 日 & 30 日 & 40 日 & 50 日 & 60 日 & 70 日 & 80日 & 90 日 & 100 日 & 加 & 少 \\
\hline 24 & $\hat{\delta}$ & 1.800 & 1.875 & 2.025 & 2.025 & & & & & & & & 225 & \\
\hline 25 & $\hat{\delta}$ & 2.400 & 2.540 & 2.500 & 2.500 & 2.600 & 2.650 & & & & & & 250 & \\
\hline 26 & $q$ & 1.900 & 1.900 & 1.950 & 2.000 & 2.050 & 2.050 & & & & & & 150 & \\
\hline 27 & & 2.000 & 1.840 & 1.850 & 1.850 & 2.020 & 2.000 & 1.875 & & & & & & 125 \\
\hline 28 & q & 2.100 & 2.020 & 2.020 & 2.020 & 2.250 & 2.320 & 2.250 & & & & & 150 & \\
\hline 29 & $\hat{\delta}$ & 1.670 & 1.700 & 1.670 & 1.750 & 1.830 & 1.720 & 1.680 & & & & & 10 & \\
\hline 30 & 今 & 2.400 & 2.350 & 1.980 & 2.130 & 2.540 & 2.450 & 2.450 & 2.580 & 2.580 & 2.650 & 2.650 & 250 & \\
\hline 31 & ક & 2.550 & 2.400 & 2.450 & 2.170 & 2.450 & 2.600 & 2.650 & 2.600 & 2.700 & 2.720 & 2.920 & 380 & \\
\hline 32 & $\uparrow$ & 2.250 & 2.250 & 2.250 & 2.320 & 2.400 & 2.320 & 2.350 & 2.350 & 2.350 & 2.500 & 2.500 & 250 & \\
\hline 體 & 减 & 少 & 4例 & 3 例 & 1冽 & 0 & 4例 & 3 例 & 1例 & 0 & 0 & 0 & & \\
\hline & & 加 & $3 / 1$ & $3 / 1$ & $4 \prime \prime$ & 8例 & 3 /I & $2 \prime \prime$ & $1 / 1$ & 1例 & 3 例 & 1例 & & \\
\hline 重 & 變化 & ヒナシ & $2 \prime \prime$ & $3 \prime$ & $4 "$ & 0 & $1 / /$ & $1 \prime \prime$ & $1 / 1$ & $2 \prime \prime$ & 0 & $2 \prime \prime$ & & \\
\hline
\end{tabular}




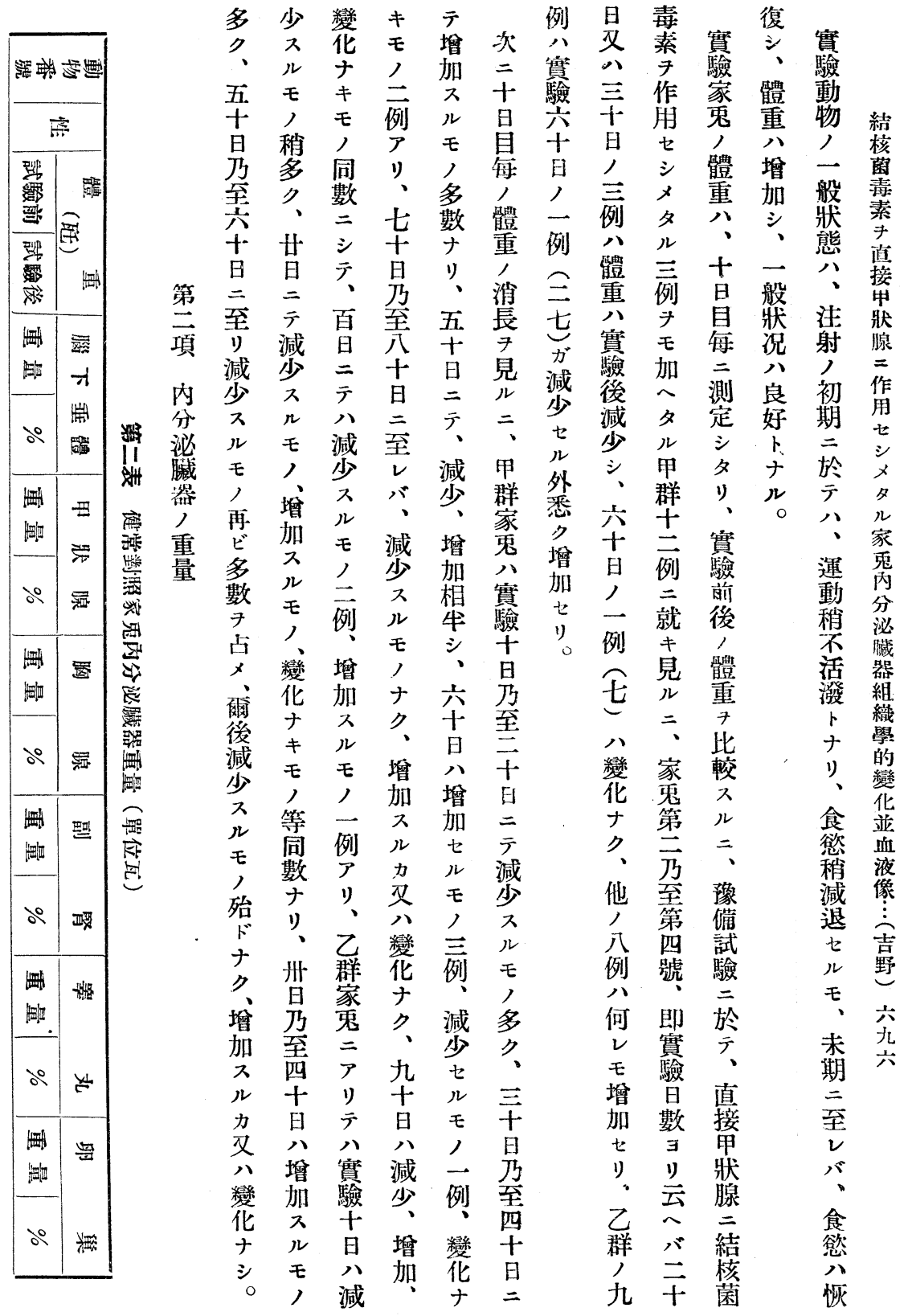




\begin{tabular}{|c|c|c|c|c|c|c|}
\hline \multirow{7}{*}{ 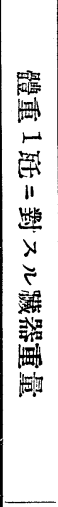 } & 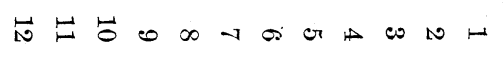 & \multicolumn{2}{|c|}{ 滥成高焉 } & & \multirow{5}{*}{ 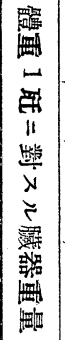 } & 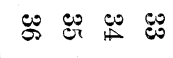 \\
\hline & 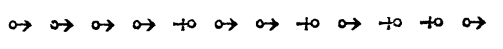 & \multicolumn{2}{|c|}{ 堂 } & & & to + to $\leftrightarrow \leftrightarrow$ \\
\hline & 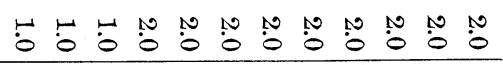 & \multirow{2}{*}{\multicolumn{2}{|c|}{ 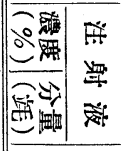 }} & & & \multirow{2}{*}{ 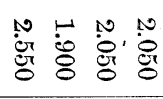 } \\
\hline & 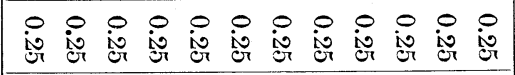 & & & & & \\
\hline & 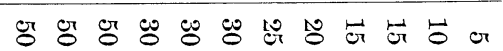 & \multicolumn{2}{|c|}{ 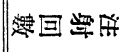 } & & & 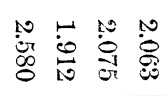 \\
\hline & 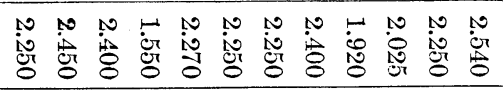 & \multirow{2}{*}{\multicolumn{2}{|c|}{ 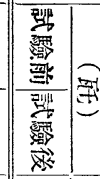 }} & & $\begin{array}{l}0 \\
0 \\
0 \\
0\end{array}$ & 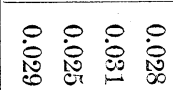 \\
\hline & 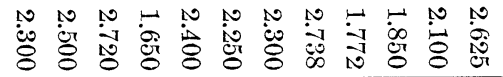 & & & & $\ddot{0}$ & $\therefore: ㅇ ㅛ ㅇ$ \\
\hline 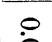 & $\circ \circ \circ \circ$ & 舟 & \multirow{4}{*}{ 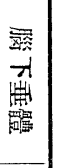 } & 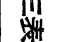 & $\infty$ & \\
\hline 高 & 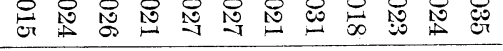 & 沕 & & & \multirow{2}{*}{ 它 } & \multirow{2}{*}{ 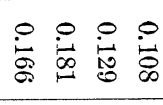 } \\
\hline :용 & \multirow{2}{*}{ 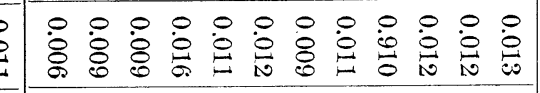 } & \multirow{2}{*}{$\therefore$} & & & & \\
\hline 寻 & & & & & \multirow{2}{*}{$\stackrel{\circ}{\circ}$} & \multirow{2}{*}{ 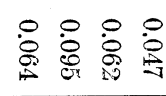 } \\
\hline$\stackrel{0}{\mathrm{e}}$ & \multirow{2}{*}{ 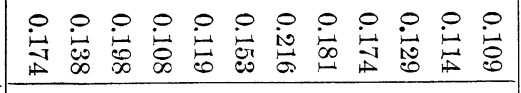 } & \multirow{2}{*}{ 漒 } & \multirow{3}{*}{ 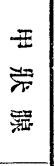 } & 年 & & \\
\hline r & & & & \multirow{5}{*}{ 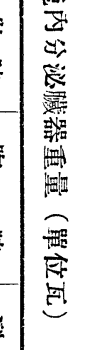 } & & \multirow{2}{*}{ 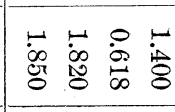 } \\
\hline$\dot{8}$ & 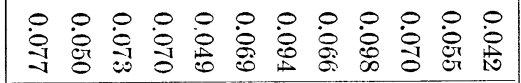 & よ゚ & & & & \\
\hline 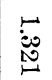 & 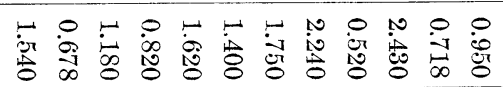 & 战 & 䍘 & & 品 & 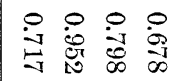 \\
\hline 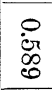 & 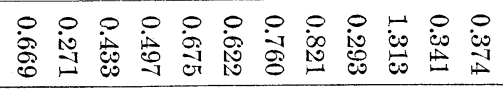 & do & 噍 & & $\begin{array}{l}0 \\
\dot{i} \infty \\
\infty \\
\infty\end{array}$ & 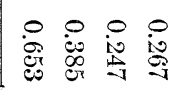 \\
\hline 总 & 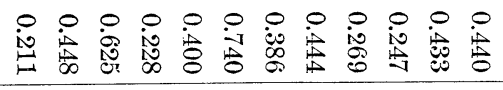 & 䵎 & 琶 & & $\dot{H}_{\vec{H}}$ & 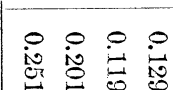 \\
\hline$\dot{\vec{g}}$ & 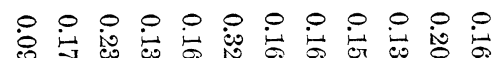 & do & \multirow[t]{2}{*}{ 嬛 } & & & \multirow{2}{*}{11 蓆 } \\
\hline & & & & & ì & \\
\hline 㟧 & 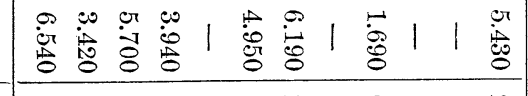 & 酽 & 蚂 & & $\leftarrow$ & \\
\hline 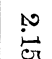 & 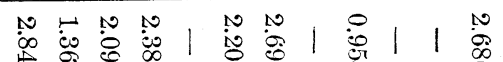 & dீ & 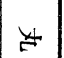 & & 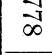 & 15 \\
\hline & 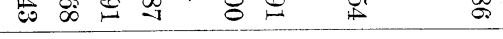 & & & & 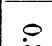 & \\
\hline $\begin{array}{l}8 \\
\text { 是 } \\
\text { 夜 }\end{array}$ & 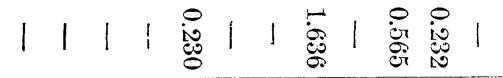 & 眐 & 娄 & & $\stackrel{\infty}{\&}$ & 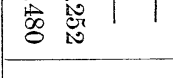 \\
\hline$\underset{:}{:}$ & 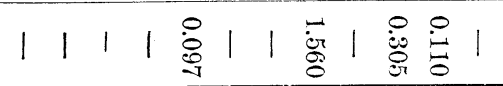 & do & 剩 & & 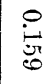 & 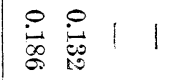 \\
\hline
\end{tabular}




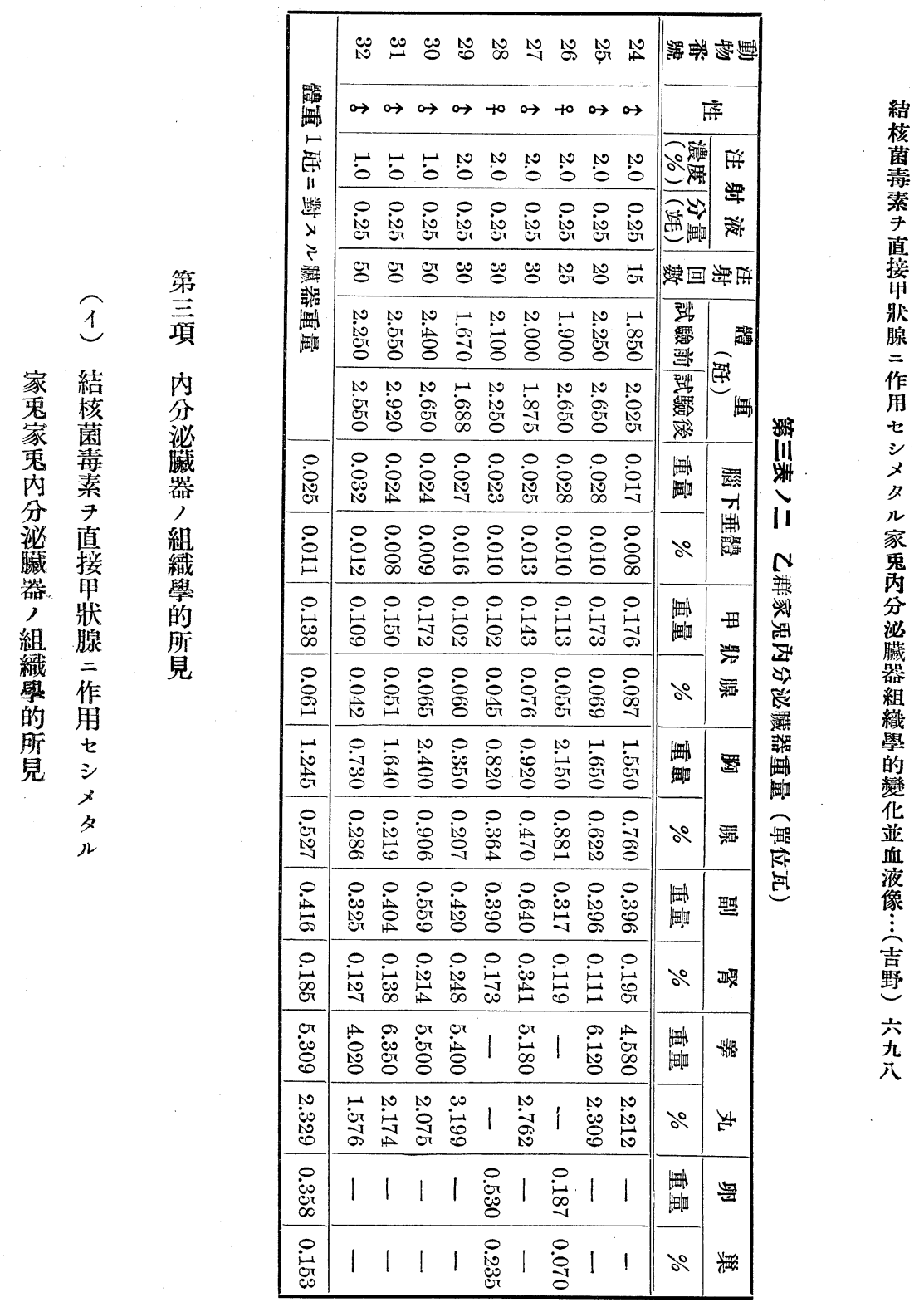




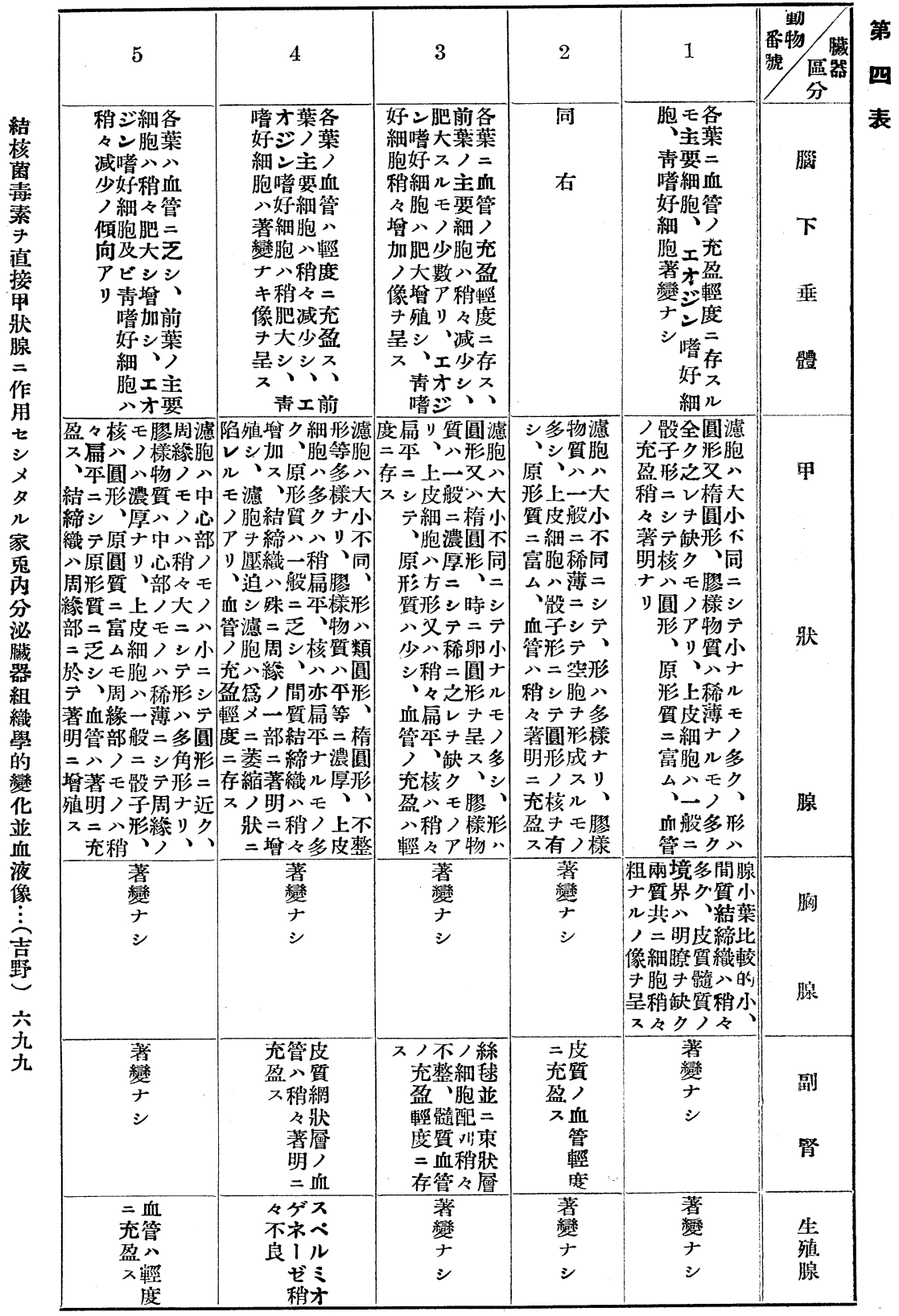




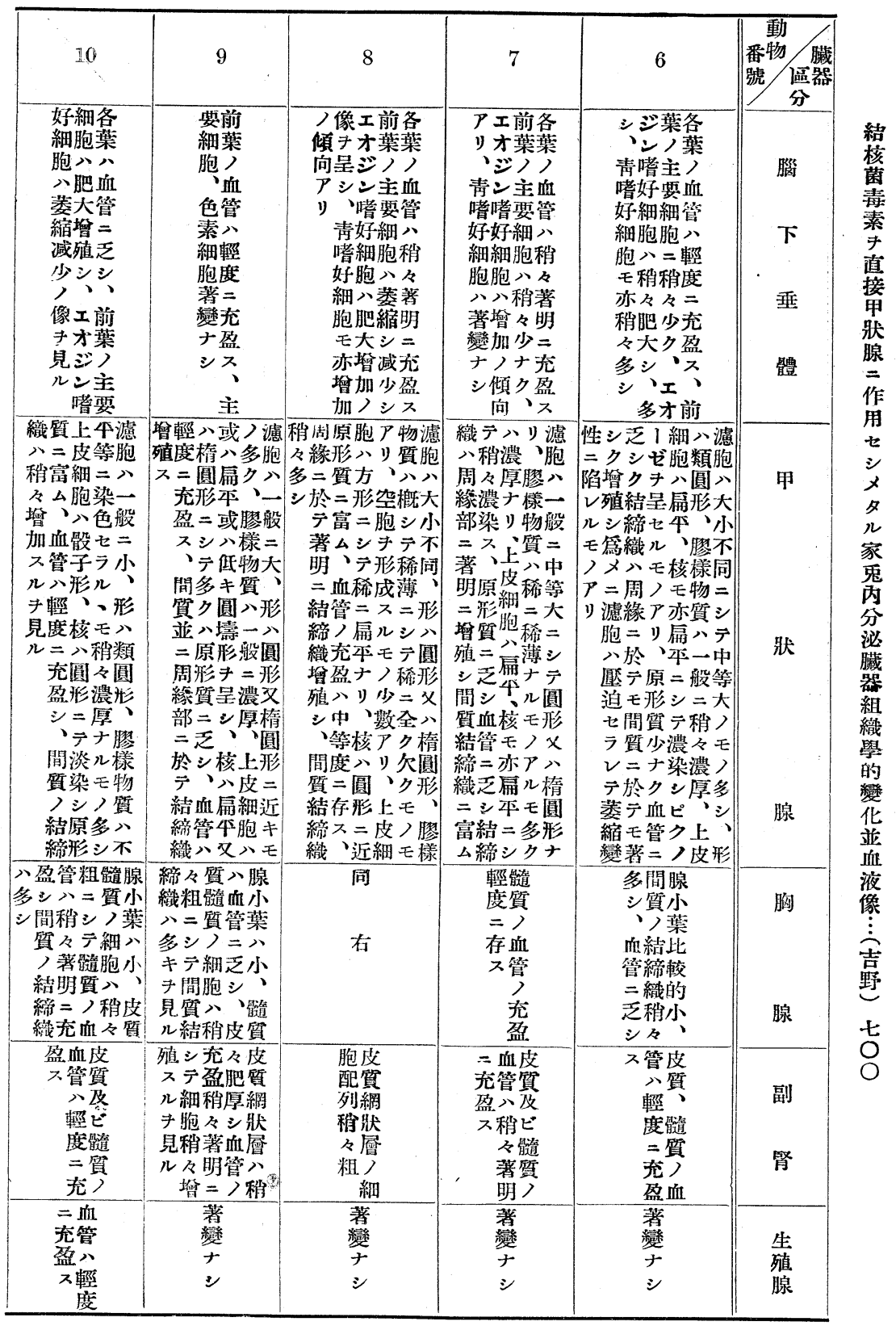




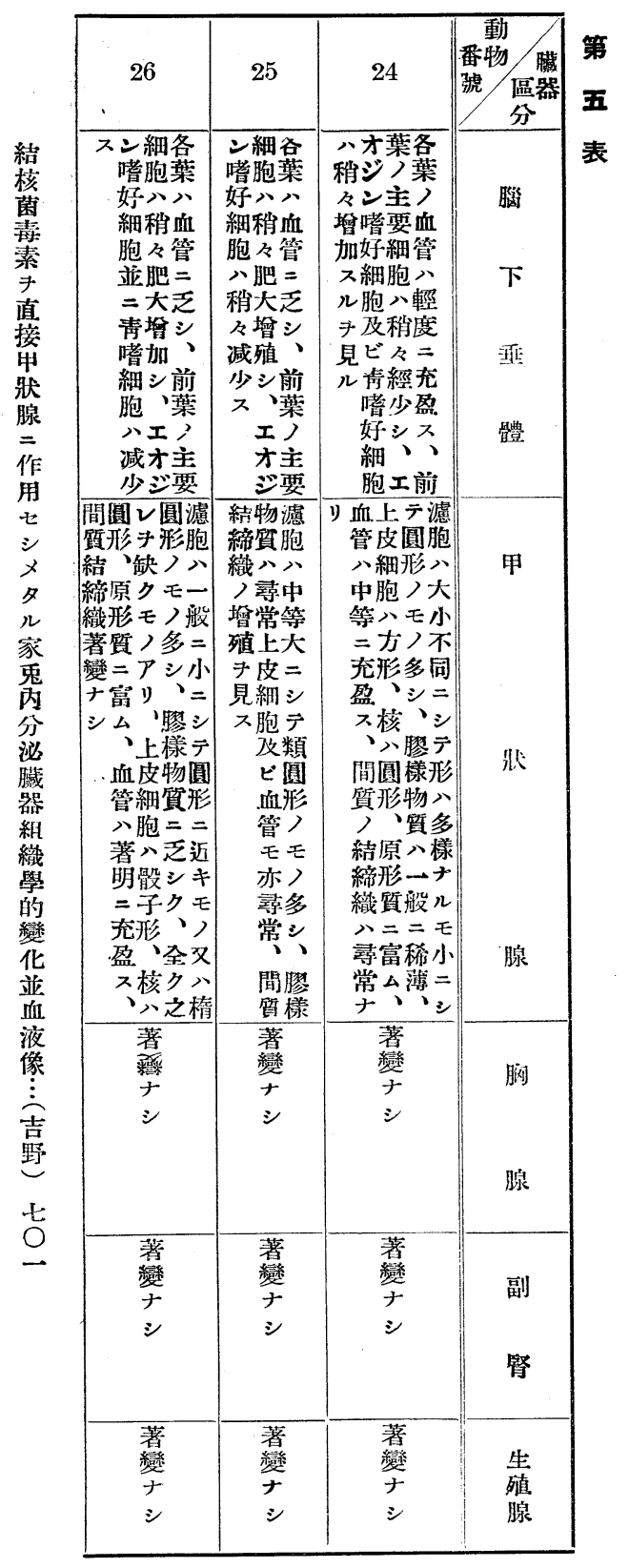

\begin{tabular}{|c|c|}
\hline 12 & 11 \\
\hline 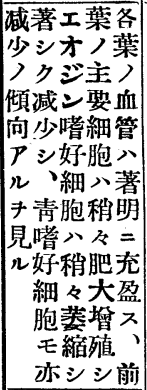 & 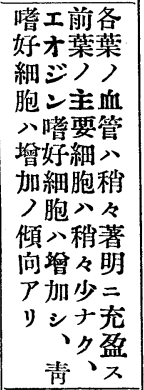 \\
\hline 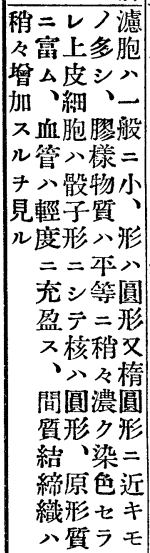 & 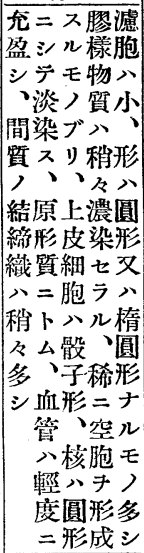 \\
\hline 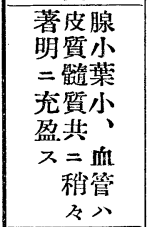 & 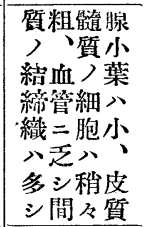 \\
\hline 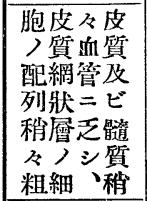 & $\begin{array}{l}\text { 著 } \\
\text { 變 } \\
\text { ナ } \\
\text { シ }\end{array}$ \\
\hline $\begin{array}{c}\text { 盈々シ精 } \\
\text { ス著血絲 } \\
\text { 明管形 } \\
\text { 二八成 } \\
\text { 充稍少 }\end{array}$ & $\begin{array}{l}=\text { 血 } \\
\text { 充管 } \\
\text { 盈少 } \\
\text { 人輕 } \\
\text { 废 }\end{array}$ \\
\hline
\end{tabular}




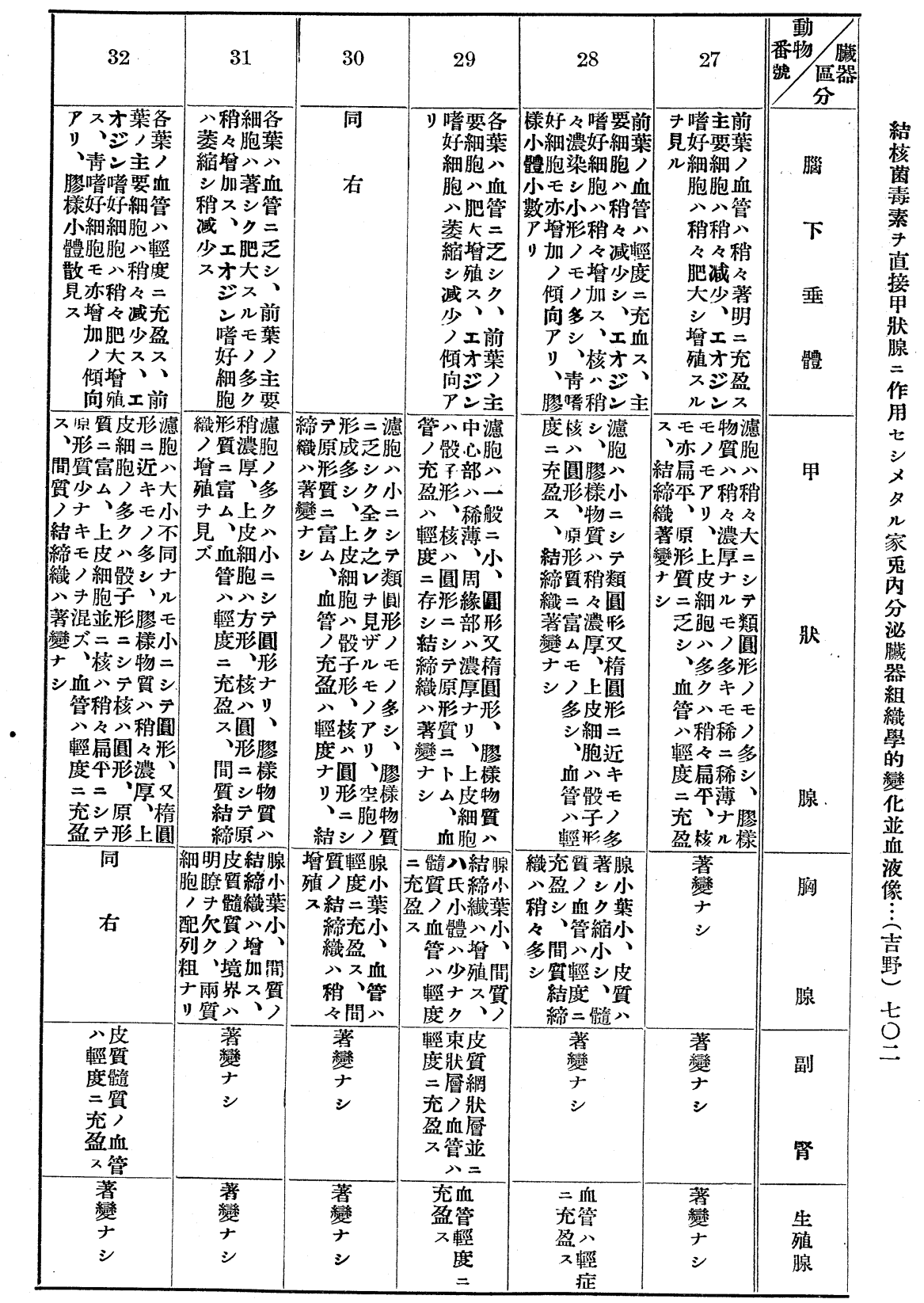




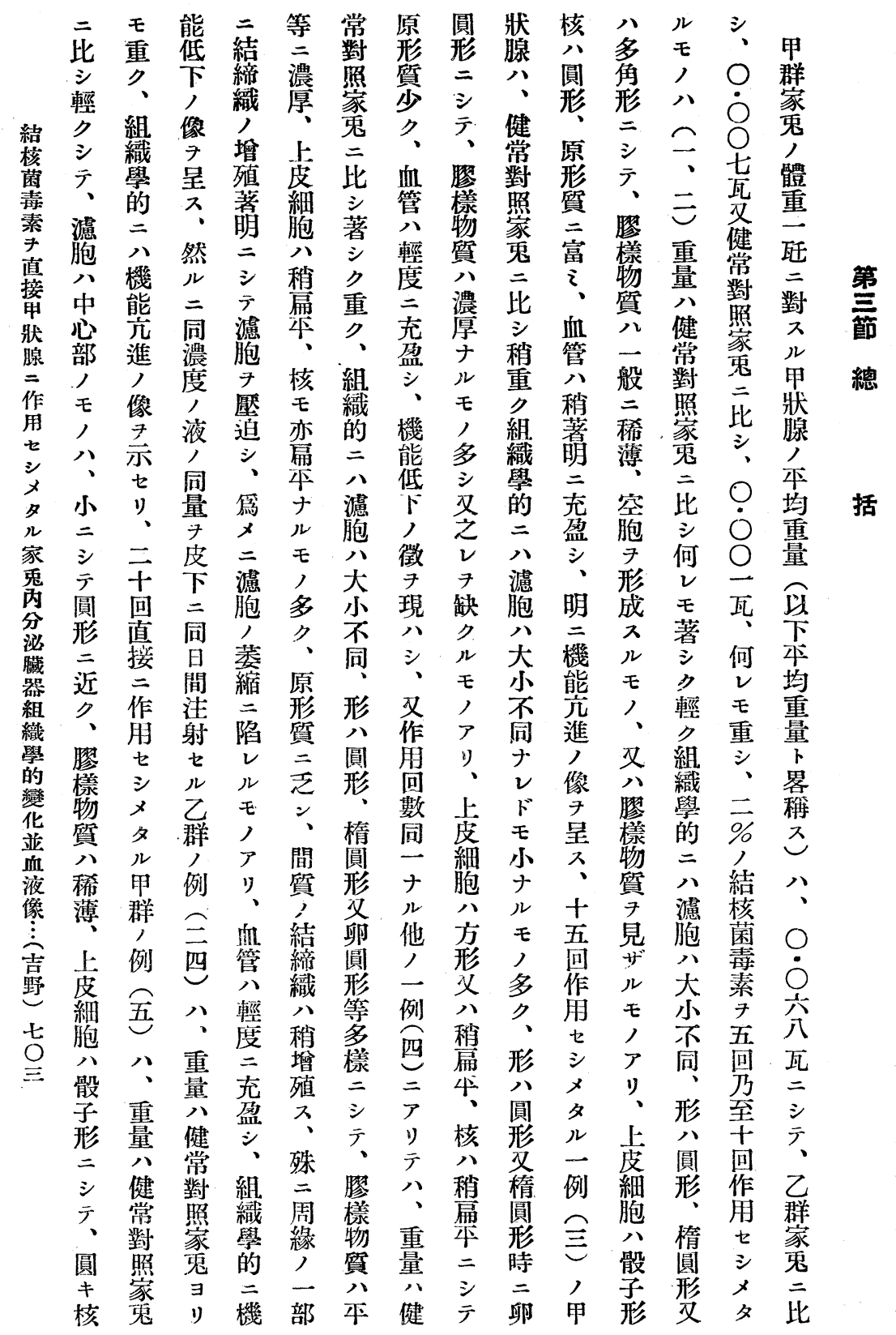




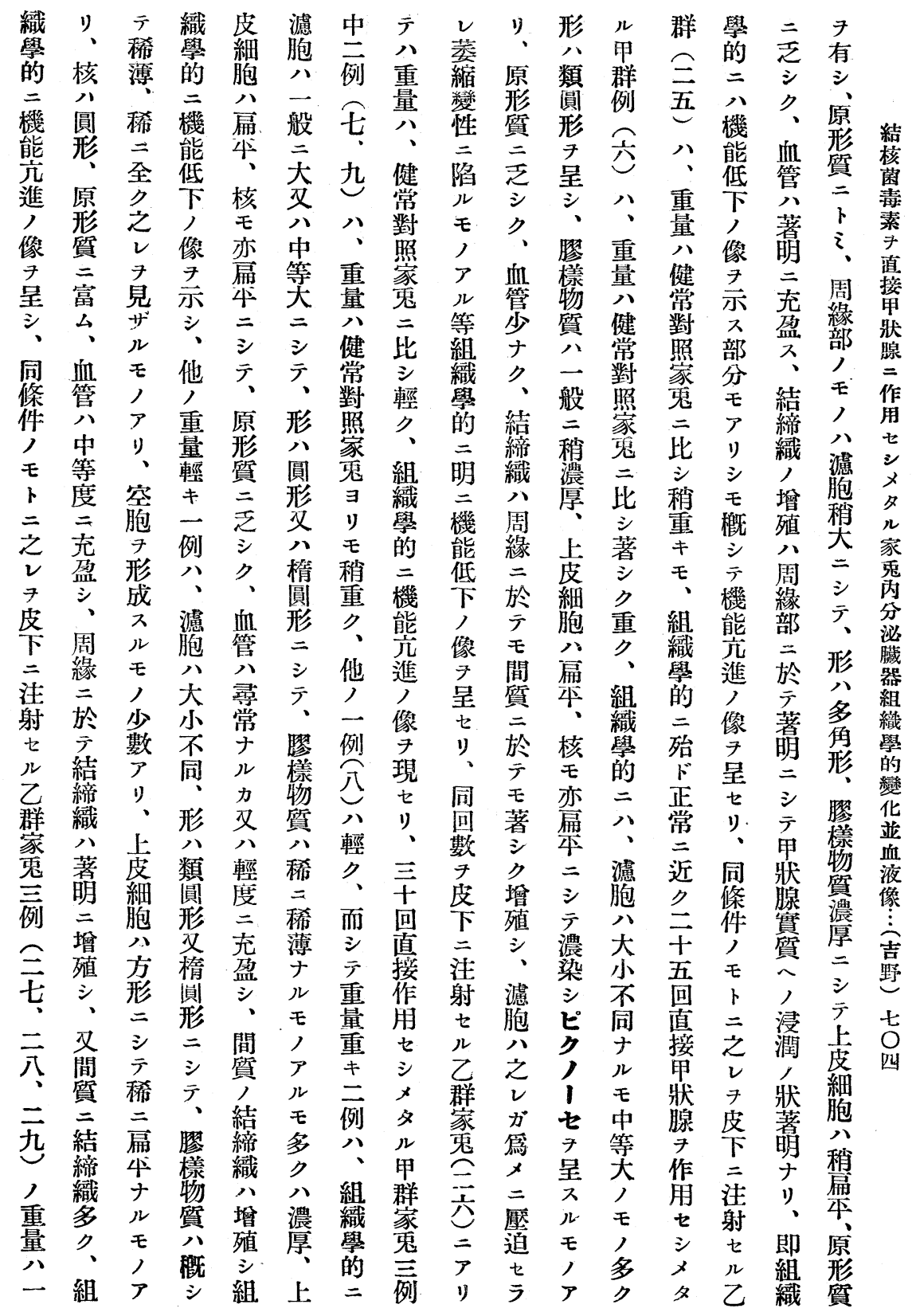




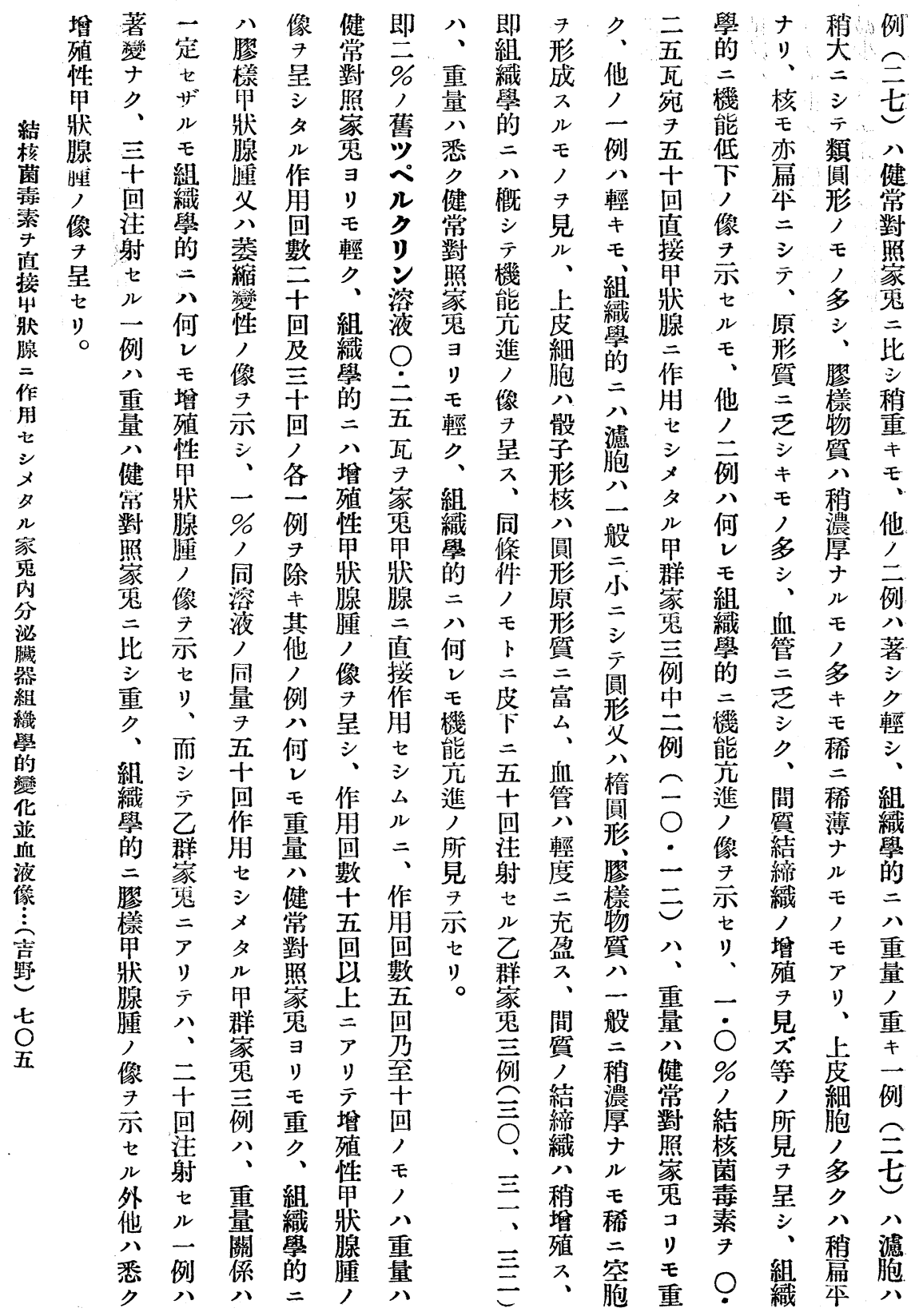




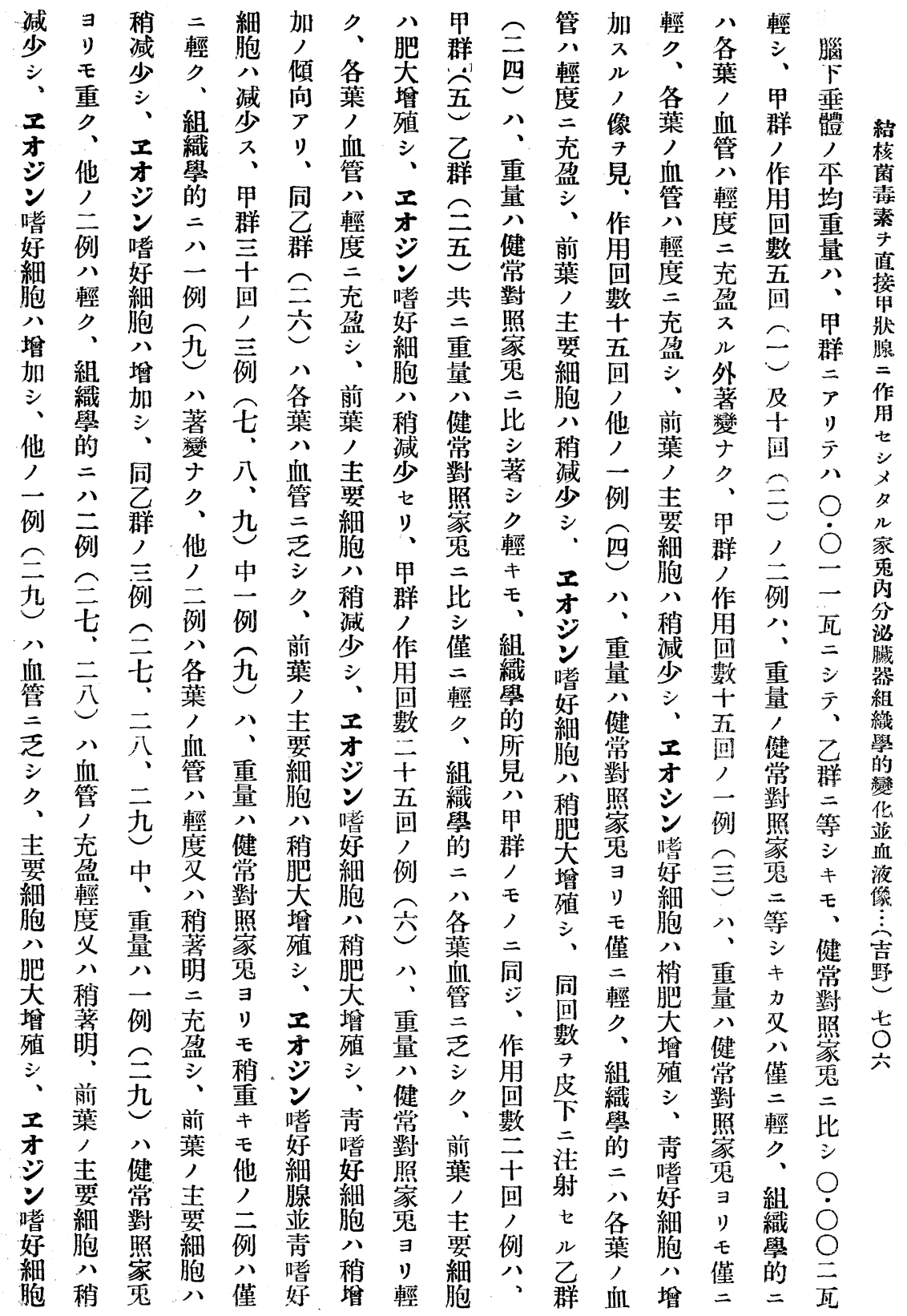




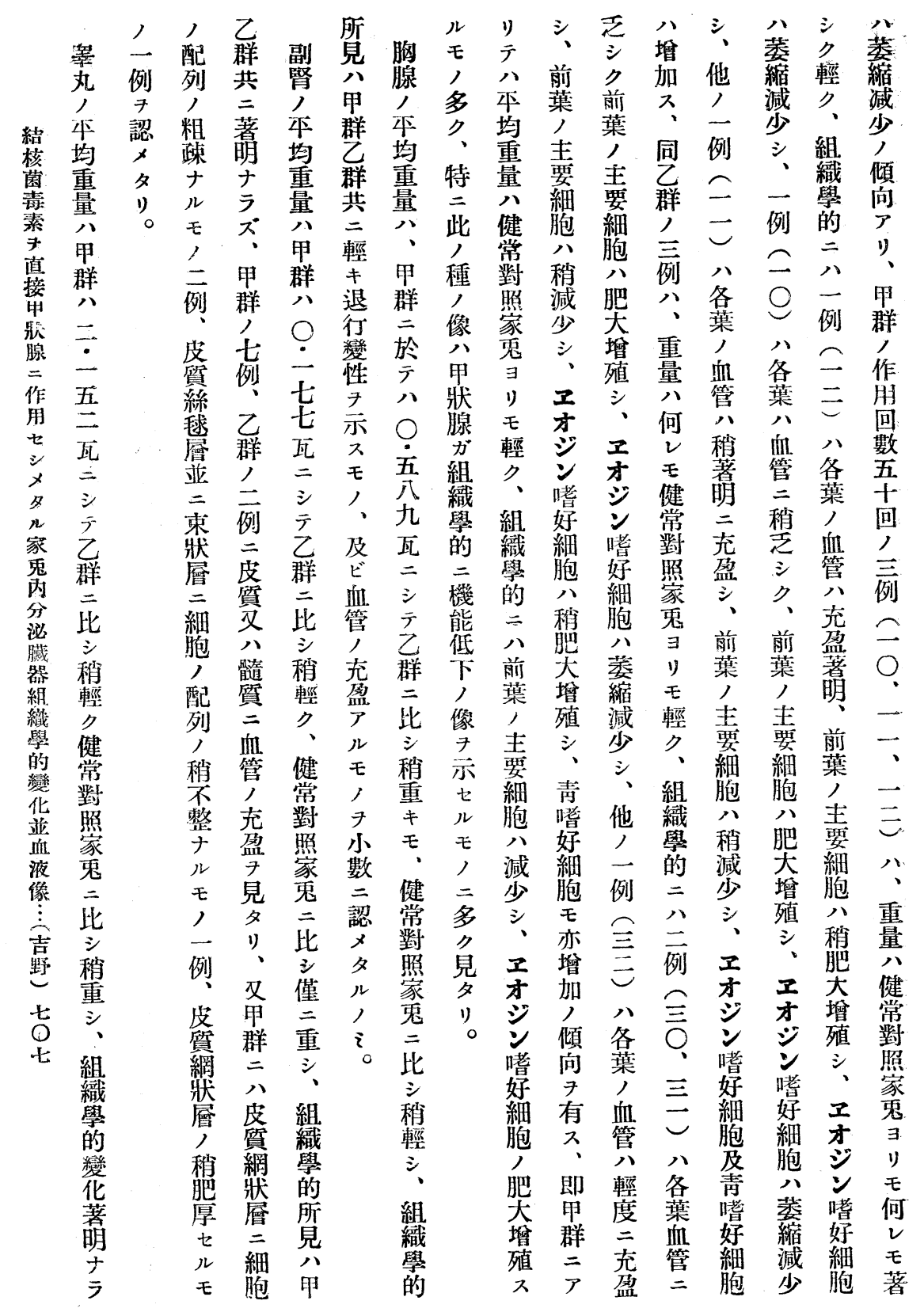




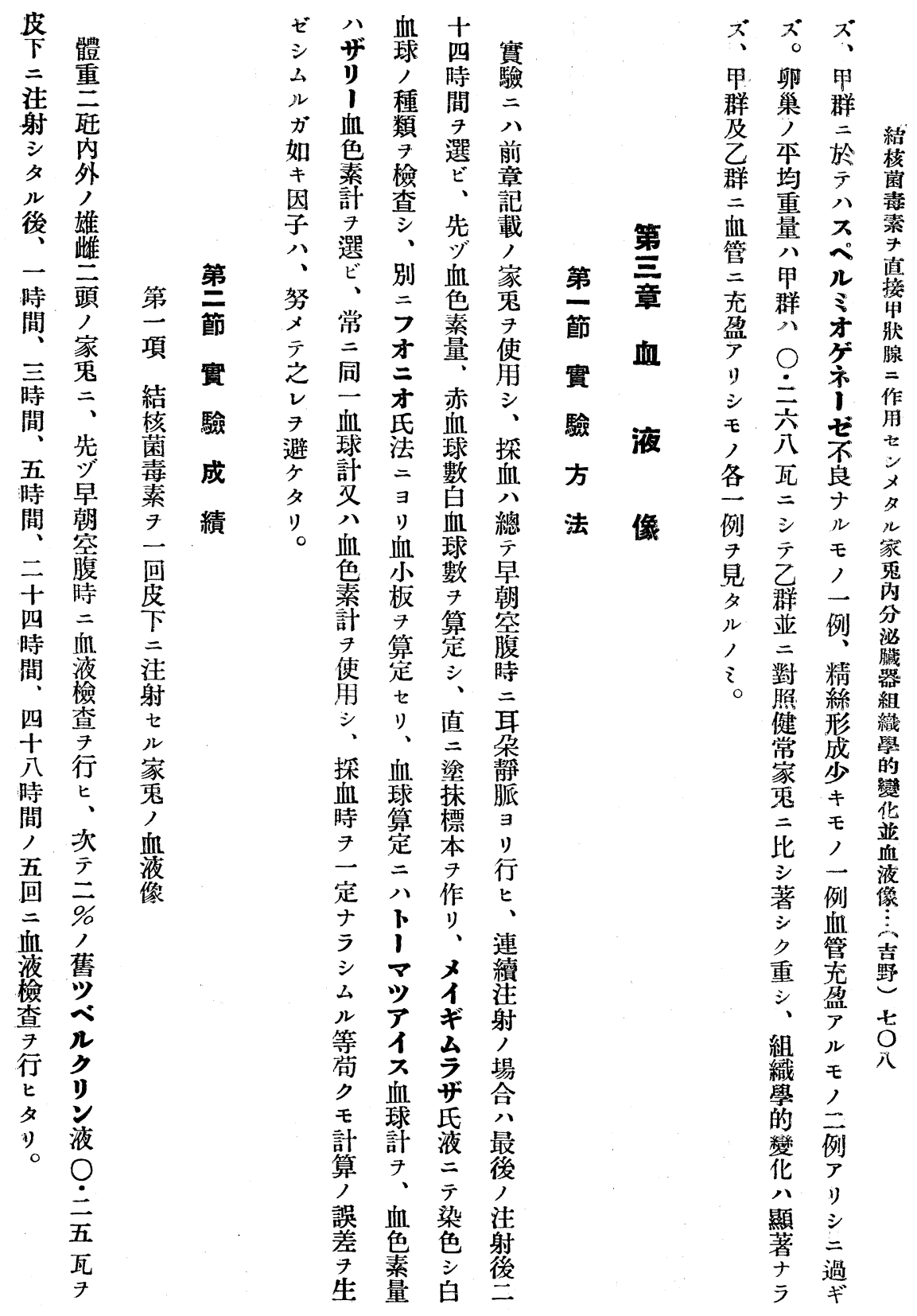




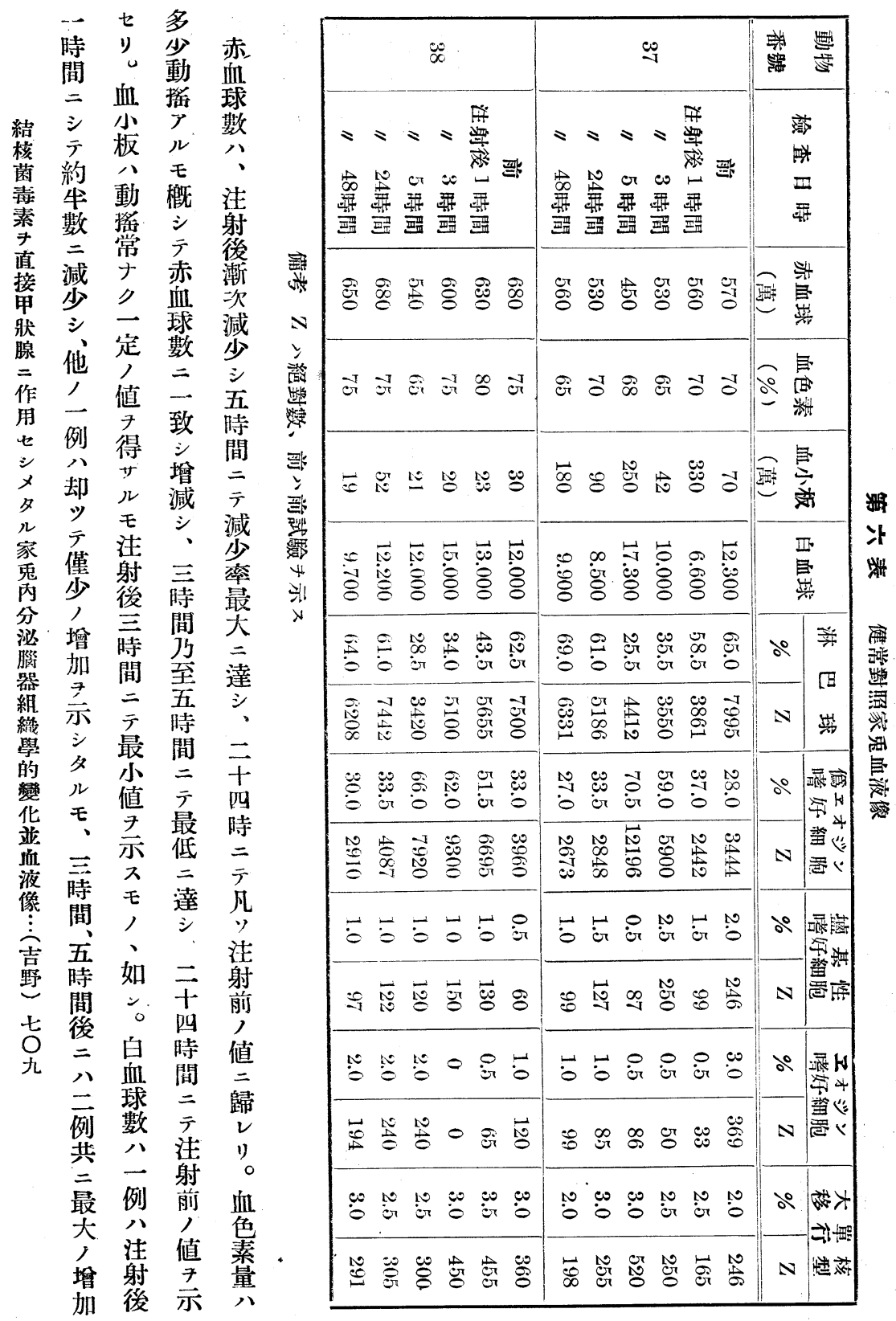




\begin{tabular}{|c|c|c|}
\hline 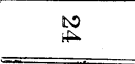 & & 害 \\
\hline$\stackrel{\infty}{\infty} \underset{\infty}{\infty}$ & & $\begin{array}{l}\text { 演 } \\
\text { 醉 }\end{array}$ \\
\hline 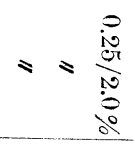 & 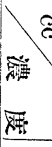 & $\sqrt{200}$ \\
\hline 5 or & & $\underset{m}{\stackrel{4}{*}}$ \\
\hline$\stackrel{8}{\circ} \stackrel{8}{\circ}$ & 琵 & 基 \\
\hline कै जै & 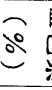 & 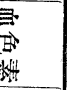 \\
\hline$\infty \dot{N}_{i}$ & 配 & 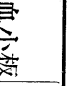 \\
\hline 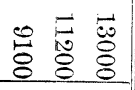 & & 焉 \\
\hline 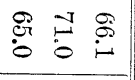 & \multirow{2}{*}{\multicolumn{2}{|c|}{ 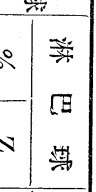 }} \\
\hline 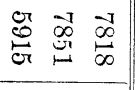 & & \\
\hline 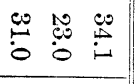 & do & $\mid$ \\
\hline 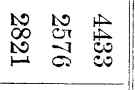 & $\mathrm{N}$ & 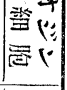 \\
\hline ir $\overrightarrow{0}$ is & $\therefore$ & 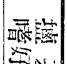 \\
\hline 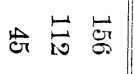 & N & 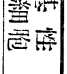 \\
\hline i & $\therefore$ & 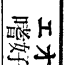 \\
\hline 合节㟧 & $N$ & 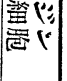 \\
\hline 0 & de & 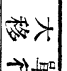 \\
\hline 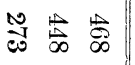 & $N$ & 崖赔 \\
\hline
\end{tabular}

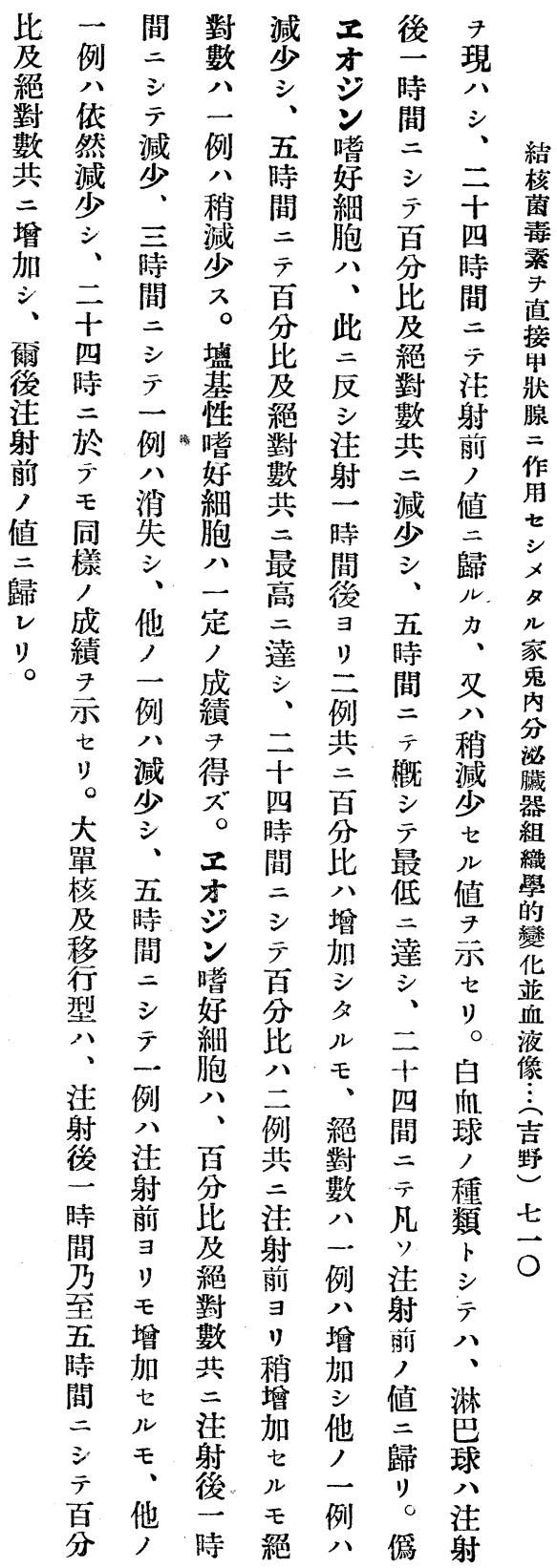




\begin{tabular}{|c|c|c|c|}
\hline$\infty$ & ה & ㅇ. & 气 \\
\hline 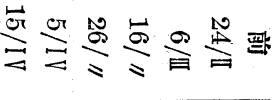 & 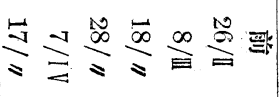 & 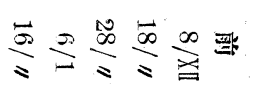 & 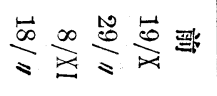 \\
\hline$s=s=s$ & $s \leqslant s \leqslant s$ & $s=s s$ & $s=s=8$ \\
\hline$\Leftrightarrow$ 웅 & $\because \stackrel{0}{\circ} \vec{*} \equiv$ & 过 & tै \\
\hline \& 엉 & 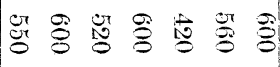 & 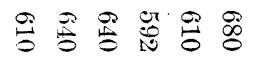 & r \\
\hline 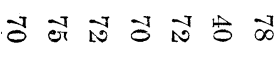 & N̂े है \& & 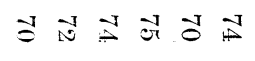 & 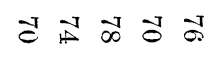 \\
\hline 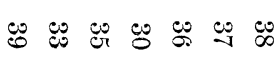 & 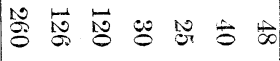 & 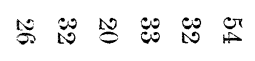 & J̄ \\
\hline 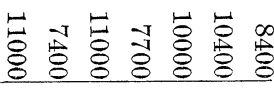 & 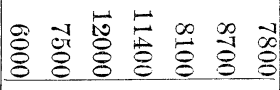 & 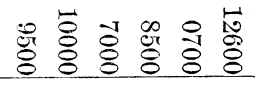 & 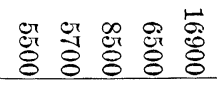 \\
\hline 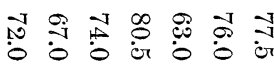 & 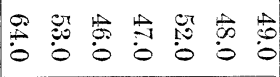 & 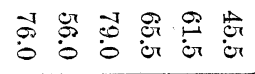 & 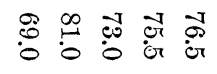 \\
\hline 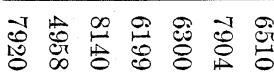 & 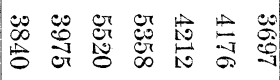 & 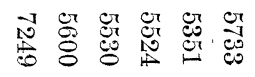 & 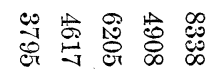 \\
\hline 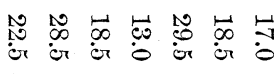 & 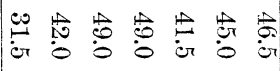 & 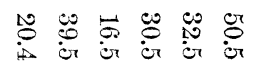 & 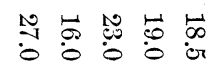 \\
\hline 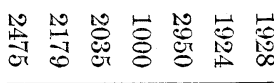 & 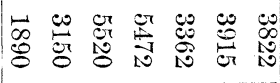 & 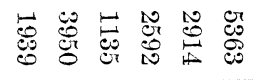 & 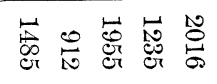 \\
\hline 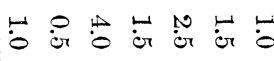 & 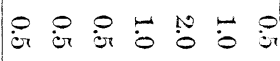 & 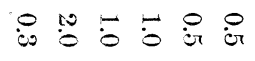 & $\overrightarrow{0}$ 昆官苛 \\
\hline 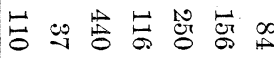 & 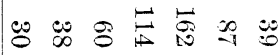 & 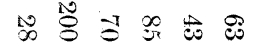 & 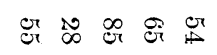 \\
\hline 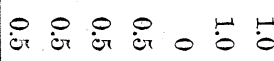 & $\dot{0} 00$ 完 $0 \overrightarrow{0} \overrightarrow{0}$ & $=00 \overrightarrow{0} \dot{0} \dot{\sigma}$ & $00 \dot{0} \ddot{0} \overrightarrow{0}$ \\
\hline छ & $\mathscr{\theta} 00 \stackrel{\mathbb{N}}{0}=\stackrel{\infty}{-\infty}$ & $000 \stackrel{\infty}{0} \dot{B}$ & 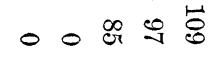 \\
\hline 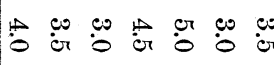 & 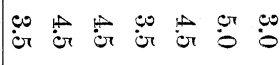 & 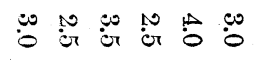 & 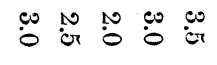 \\
\hline 啹 & N & 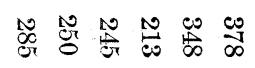 & 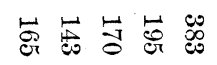 \\
\hline
\end{tabular}




\begin{tabular}{|c|c|c|}
\hline 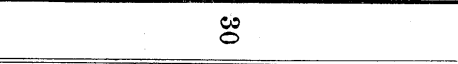 & 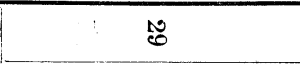 & 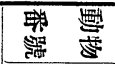 \\
\hline 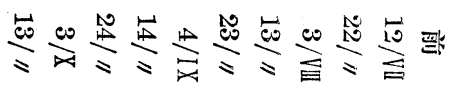 & 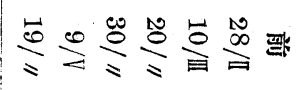 & 严㐭 \\
\hline 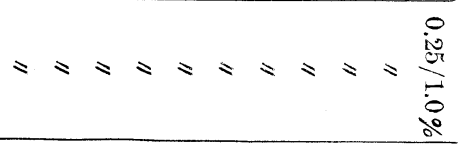 & $s=s \leqslant s$ & 緢 \\
\hline 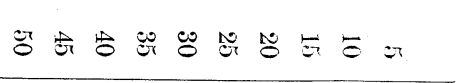 & 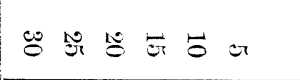 & 是 \\
\hline 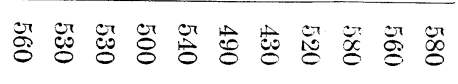 & $\ddot{8} 8$ \& & 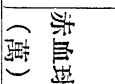 \\
\hline 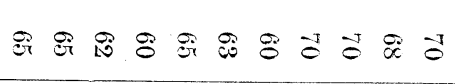 & Oै & 举 \\
\hline 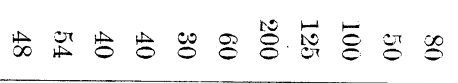 & 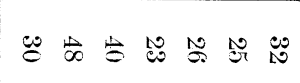 & 焉 \\
\hline 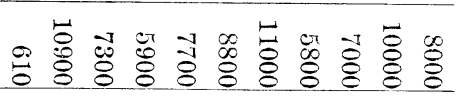 & 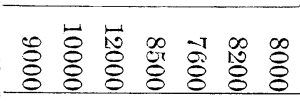 & 震 \\
\hline 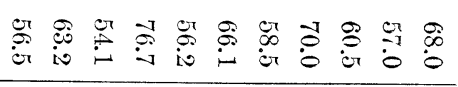 & 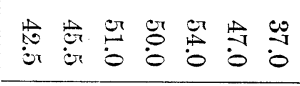 & de \\
\hline 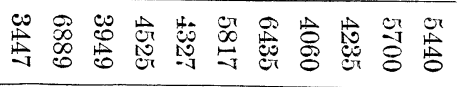 & 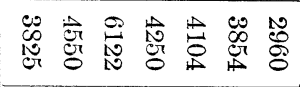 & 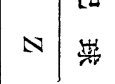 \\
\hline 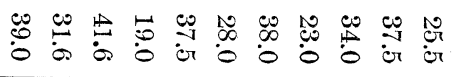 & 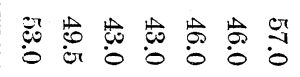 & 이래 \\
\hline 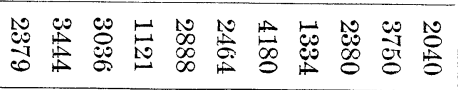 & 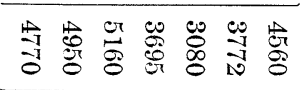 & N|望觉 \\
\hline 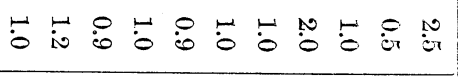 & 잉 & $\therefore 0$ 悲瞵 \\
\hline 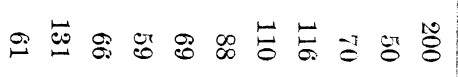 & 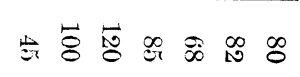 & 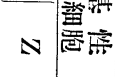 \\
\hline 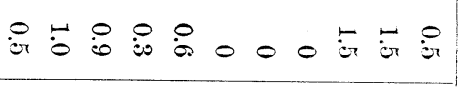 & $\ddot{\theta}=0 \ddot{\dot{r}} \dot{0} \ddot{0} \dot{0}$ & 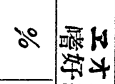 \\
\hline ஸ્今 & 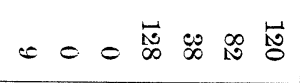 & 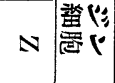 \\
\hline 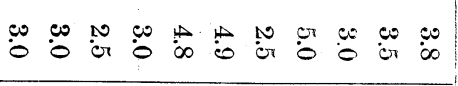 & 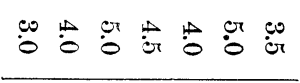 & $\therefore x$ \\
\hline 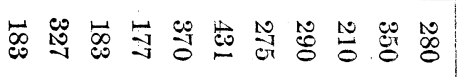 & 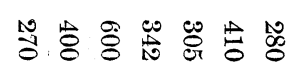 & 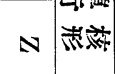 \\
\hline
\end{tabular}




\begin{tabular}{|c|c|}
\hline$\stackrel{40}{\infty}$ & $\stackrel{\infty}{-\infty}$ \\
\hline 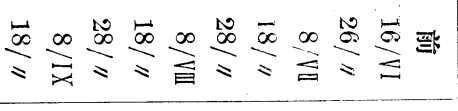 & 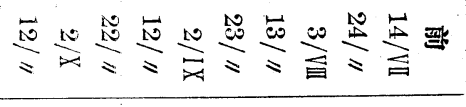 \\
\hline$s=s z s=s z$ & $s z s z s z s s$ \\
\hline 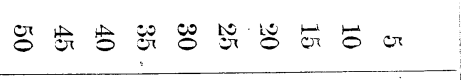 & 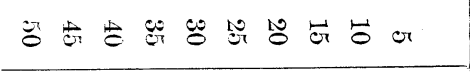 \\
\hline 装 & 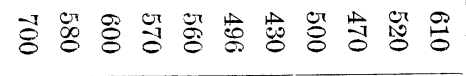 \\
\hline 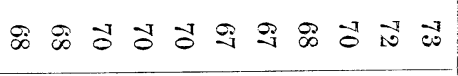 & 知 \\
\hline 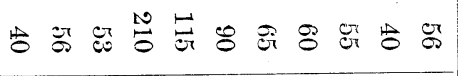 & 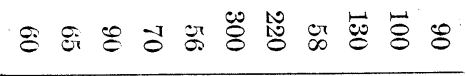 \\
\hline 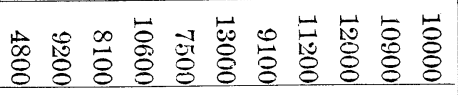 & 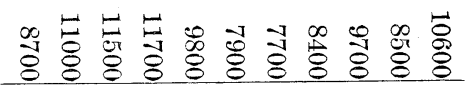 \\
\hline 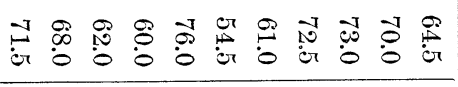 & 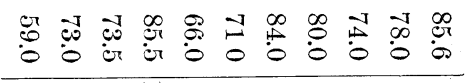 \\
\hline 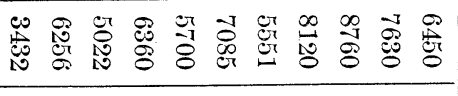 & 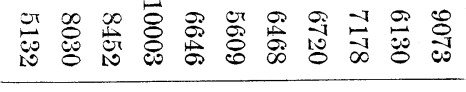 \\
\hline 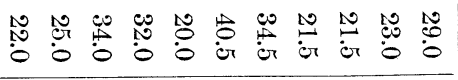 & 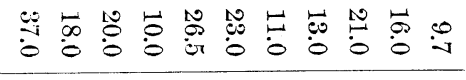 \\
\hline 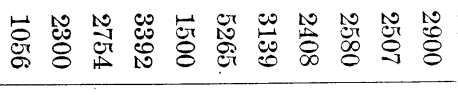 & 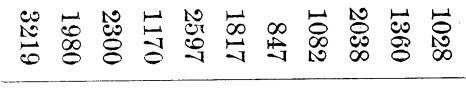 \\
\hline 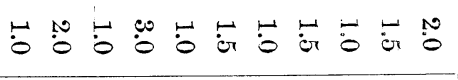 & 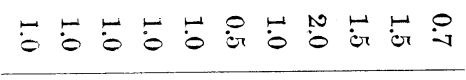 \\
\hline 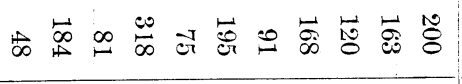 & 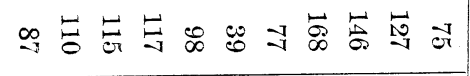 \\
\hline 。 & 。 \\
\hline 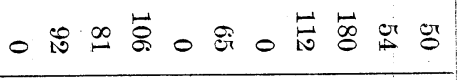 & 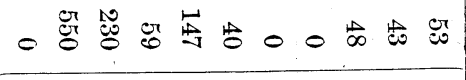 \\
\hline 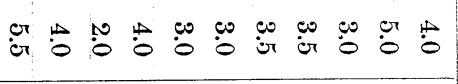 & 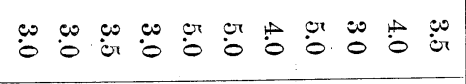 \\
\hline 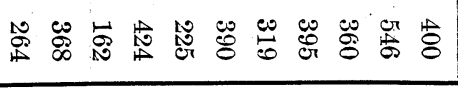 & 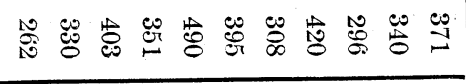 \\
\hline
\end{tabular}




\begin{tabular}{|c|c|c|c|c|c|c|c|}
\hline or & $\triangle$ & $\infty$ & ה & 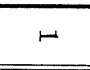 & 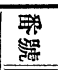 & 囬 & \\
\hline 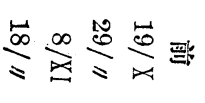 & $\stackrel{\infty}{\infty} \stackrel{\infty}{=} \stackrel{\infty}{\infty}$ & $\stackrel{\infty}{\equiv} \stackrel{\infty}{\infty} \underset{4}{\infty}$ & 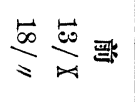 & $\stackrel{\infty}{\Perp}$ & 严 & 涼 & \\
\hline$s=8 s$ & $s \leqslant s$ & $s \leqslant s$ & 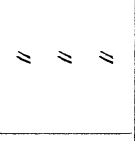 & 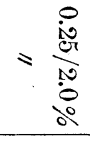 & 編 & 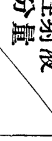 & \\
\hline 숭 峁若 & $\vec{c} \cdot \vec{\theta}$ & $\vec{c} b \vec{\theta}$ & $\vec{\sigma}$ & er & & & \\
\hline 공 \& & \&े 용 \& 8 & 芯芯芯芯 & 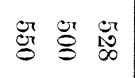 & $\underset{\infty}{\stackrel{\infty}{\infty}}$ & 跣 & 窟 & \\
\hline 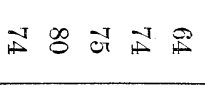 & 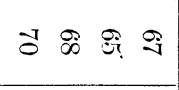 & 10. & $g 8$ & $\therefore 0$ & ह5? & 胥 & \\
\hline 봉 㟔虫 & 㟧 & 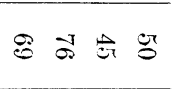 & $\vec{t} \vec{b}: 8$ & $\stackrel{5}{\circ}$ & & 管 & \\
\hline 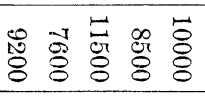 & 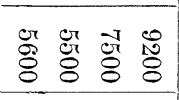 & 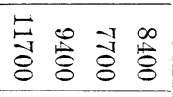 & $\begin{array}{lll}\infty & 0 & 0 \\
8 & 8 & 8 \\
8 & 8\end{array}$ & 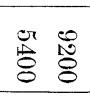 & & 震 & \\
\hline 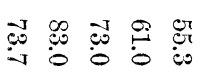 & 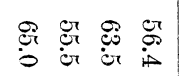 & 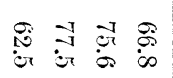 & 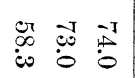 & 总 & வீ & \multirow{2}{*}{ 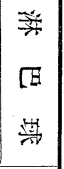 } & 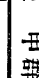 \\
\hline 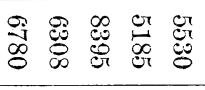 & 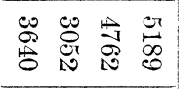 & 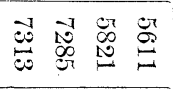 & 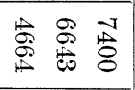 & 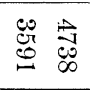 & $\mathbf{N}$ & & 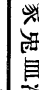 \\
\hline 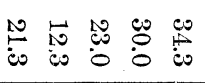 & 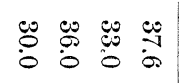 & 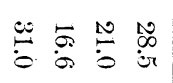 & 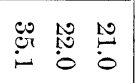 & 范 & $\therefore$ & \multirow{2}{*}{ 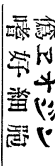 } & 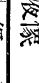 \\
\hline 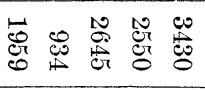 & 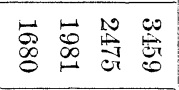 & 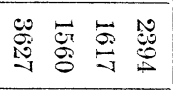 & 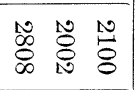 & 岕营 & $\mathbf{N}$ & & \\
\hline 이 & $\vec{b} \vec{b} \overrightarrow{0} \overrightarrow{0}$ & $\overrightarrow{0}: \dot{0}: 0$ & 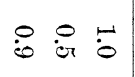 & 它 $\overrightarrow{0}$ & do & \multirow{2}{*}{ 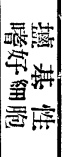 } & \\
\hline 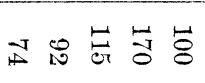 & 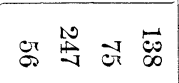 & 카요 & $\overrightarrow{10}$ के & $\underset{v}{0}$ & $\mathrm{~N}$ & & \\
\hline $0 \stackrel{P}{\circ} 0 \dot{0} \stackrel{1}{0}$ & $\vec{\circ}$ 앙 & $\dot{0}: \dot{0} 0$ & 0 웅 & $\circ$ 웅 & do & \multirow{2}{*}{ 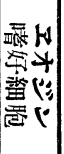 } & \\
\hline$\circ: \ddot{0} \circ \stackrel{10}{8}$ & 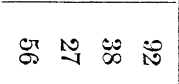 & 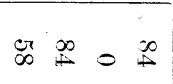 & 0 से $\overrightarrow{8}$ & 0 吕 & $心$ & & \\
\hline $\overrightarrow{\text { iv }} \overrightarrow{~ क o ~}$ & $\begin{array}{llll}0 & 0 \\
0 & 0 & 0 & 0 \\
0\end{array}$ & $\overrightarrow{0}$ & 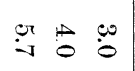 & r & $\therefore$ & 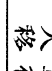 & \\
\hline 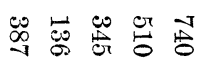 & $\vec{\circ}$ & 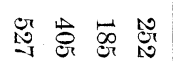 & 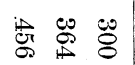 & $\overrightarrow{D_{0}^{\circ}}$ & $N$ & 崖出 & \\
\hline
\end{tabular}




\begin{tabular}{|c|c|c|c|}
\hline- & 5 & 4 & $\circ$ \\
\hline 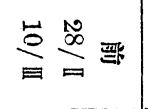 & 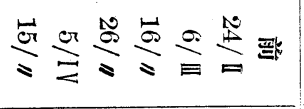 & 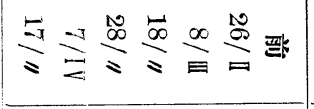 & 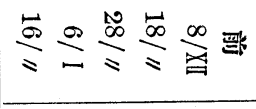 \\
\hline$=: s$ & $s=s z=$ & $s=s$ & $=s=s$ \\
\hline or or & 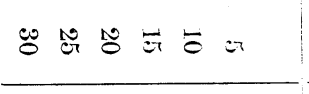 & 总 & 怘 \\
\hline 哭密 & 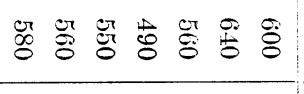 & 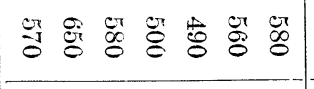 & 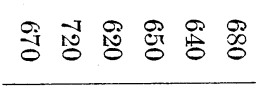 \\
\hline 도 & 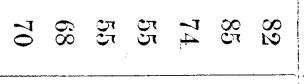 & 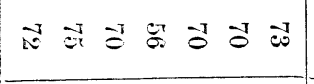 & 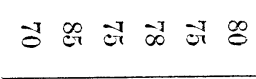 \\
\hline$\vec{G}$ 总巻 & 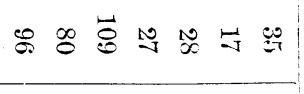 & 足 & 岁点品品 \\
\hline 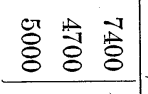 & 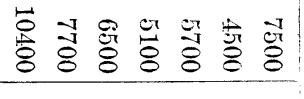 & 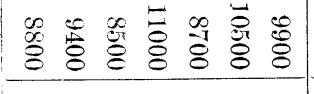 & 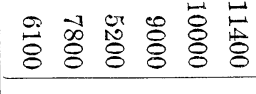 \\
\hline 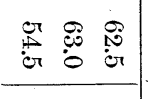 & 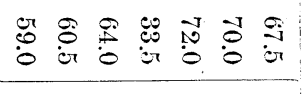 & 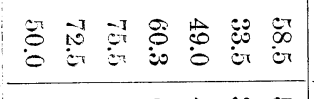 & 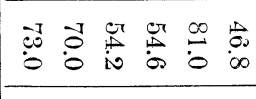 \\
\hline 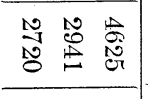 & 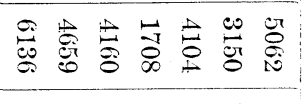 & 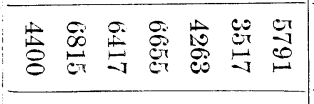 & 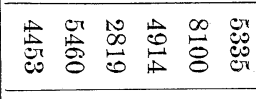 \\
\hline 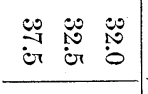 & 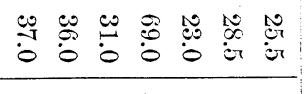 & 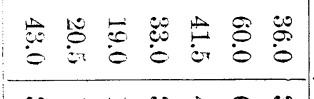 & 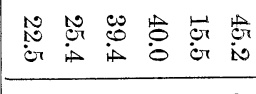 \\
\hline 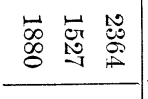 & 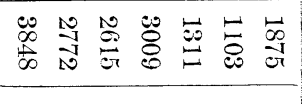 & 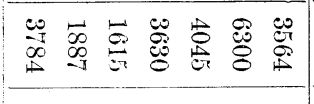 & 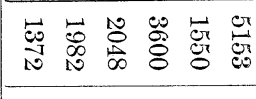 \\
\hline 果落学 & 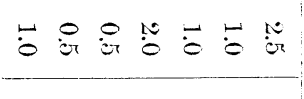 & 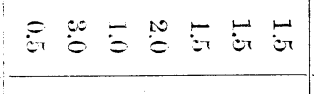 & 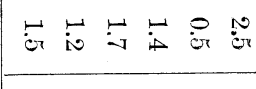 \\
\hline 总品密 & 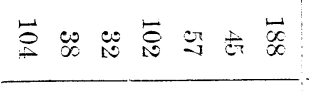 & 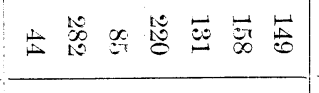 & 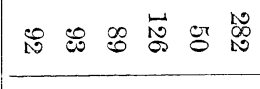 \\
\hline 000 & $00=000.8$ & $\bar{i}=8 \begin{array}{c}B \\
\dot{B}\end{array}$ & 00000 \\
\hline 001 & $000=00 \%$ & 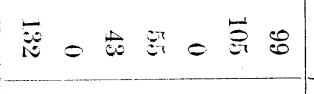 & 000000 薄 \\
\hline 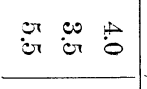 & 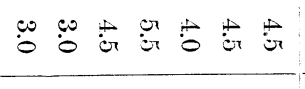 & 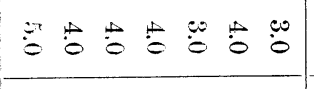 & $\dddot{0}_{0}^{0}$ \\
\hline 䓵䓵器 & 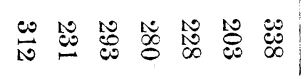 & 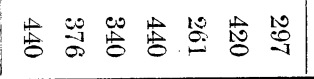 & 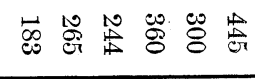 \\
\hline
\end{tabular}




\begin{tabular}{|c|c|c|c|c|}
\hline & 5 & & 辈 & 要 \\
\hline 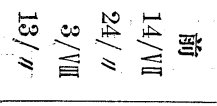 & 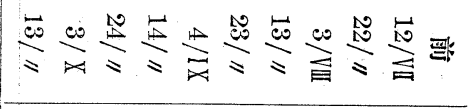 & 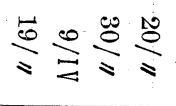 & 严 & \\
\hline$s=s s$ & 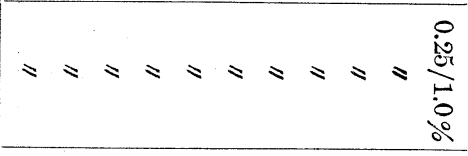 & $s s s$ & 酸 & \\
\hline 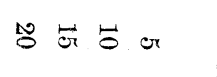 & 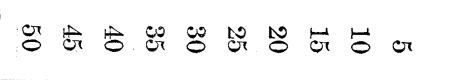 & 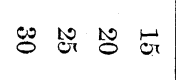 & 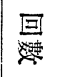 & \\
\hline 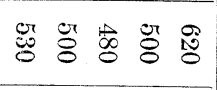 & 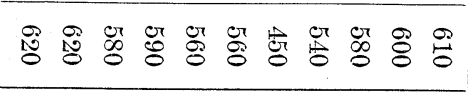 & 夈 & 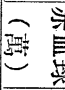 & \\
\hline \&i $\mathcal{i}$ \& $\&$ i & 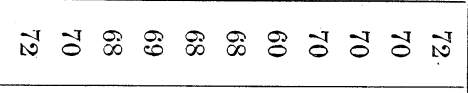 & Is $\&$ i 8 & @高 & 厲 \\
\hline 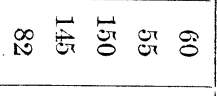 & No & 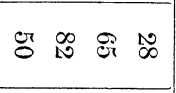 & $\underbrace{2}$ & 产 \\
\hline 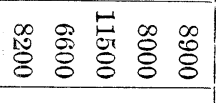 & 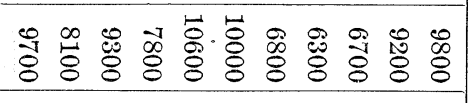 & 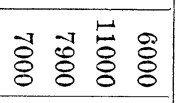 & & 焉 \\
\hline 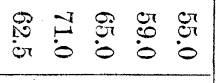 & 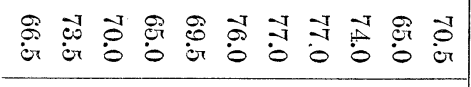 & 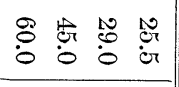 & \multirow{2}{*}{\multicolumn{2}{|c|}{ - }} \\
\hline 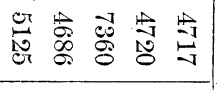 & 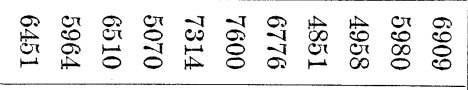 & 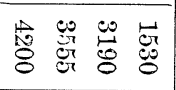 & & \\
\hline 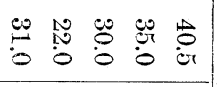 & 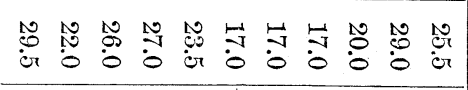 & 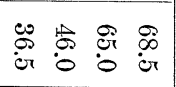 & $\therefore 0$ & 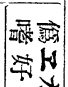 \\
\hline 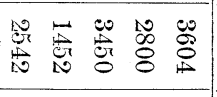 & 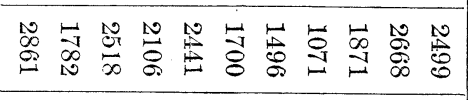 & 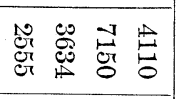 & $\mathrm{N}$ & 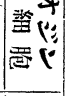 \\
\hline ㅇ & 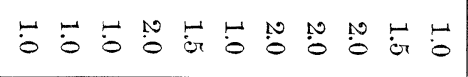 & 앙 & de & 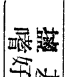 \\
\hline 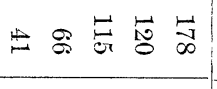 & 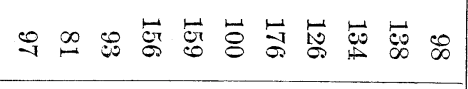 & 然 & $\mathrm{N}$ & $\mid$ \\
\hline 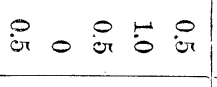 & 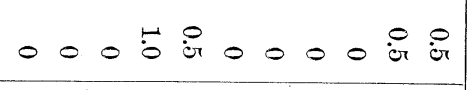 & $00 \begin{array}{llll}0 & 0 & 0 & 0 \\
0 & 0\end{array}$ & 20 & 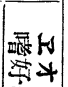 \\
\hline 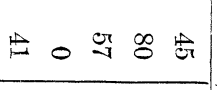 & 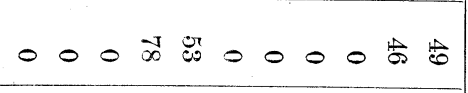 & $\circ \circ 8 \tilde{8}:$ & $\mathbf{N}$ & 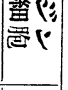 \\
\hline 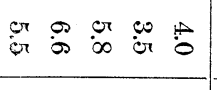 & 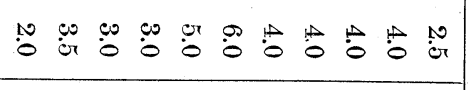 & 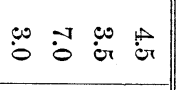 & de & $x$ \\
\hline 点 怘 & 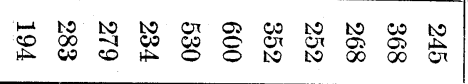 & 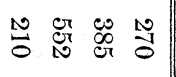 & $\mathbf{N}$ & 崖到 \\
\hline
\end{tabular}




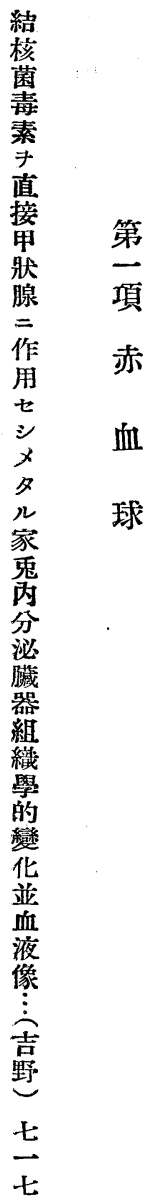

\begin{tabular}{|c|c|}
\hline $\overrightarrow{0}$ & $\Xi$ \\
\hline 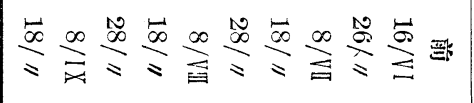 & 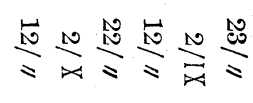 \\
\hline$s=s z=s z=s$ & $s=s s=$ \\
\hline 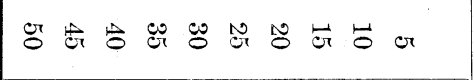 & 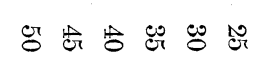 \\
\hline 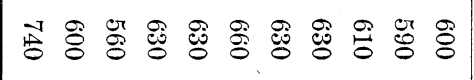 & 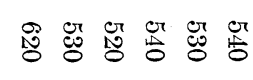 \\
\hline \& & 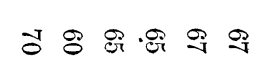 \\
\hline 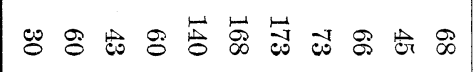 & 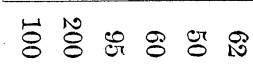 \\
\hline 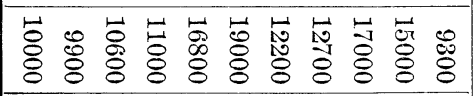 & 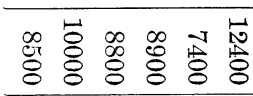 \\
\hline 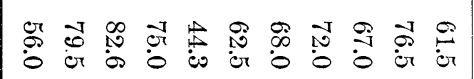 & 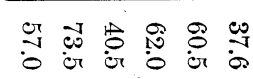 \\
\hline 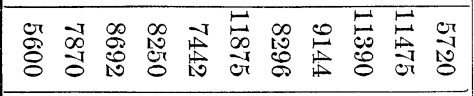 & 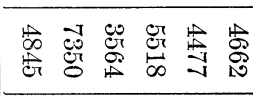 \\
\hline 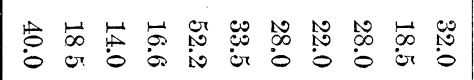 & 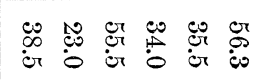 \\
\hline 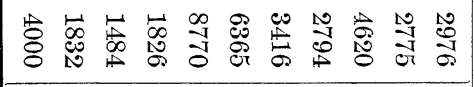 & 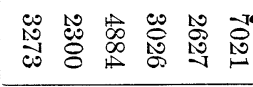 \\
\hline 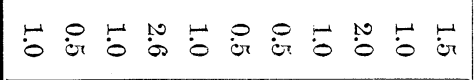 & 붕 \\
\hline 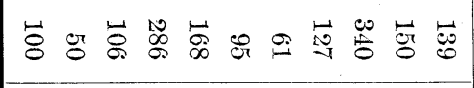 & $\infty \overrightarrow{8}$ \\
\hline 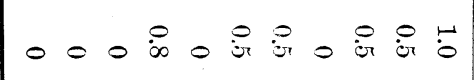 & ○ ○ें \\
\hline 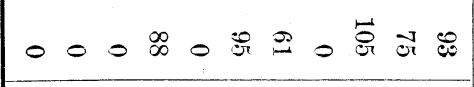 & 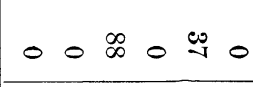 \\
\hline 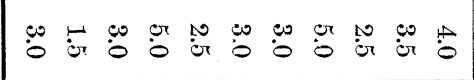 & 应 \\
\hline 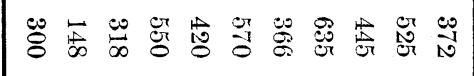 & 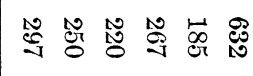 \\
\hline
\end{tabular}



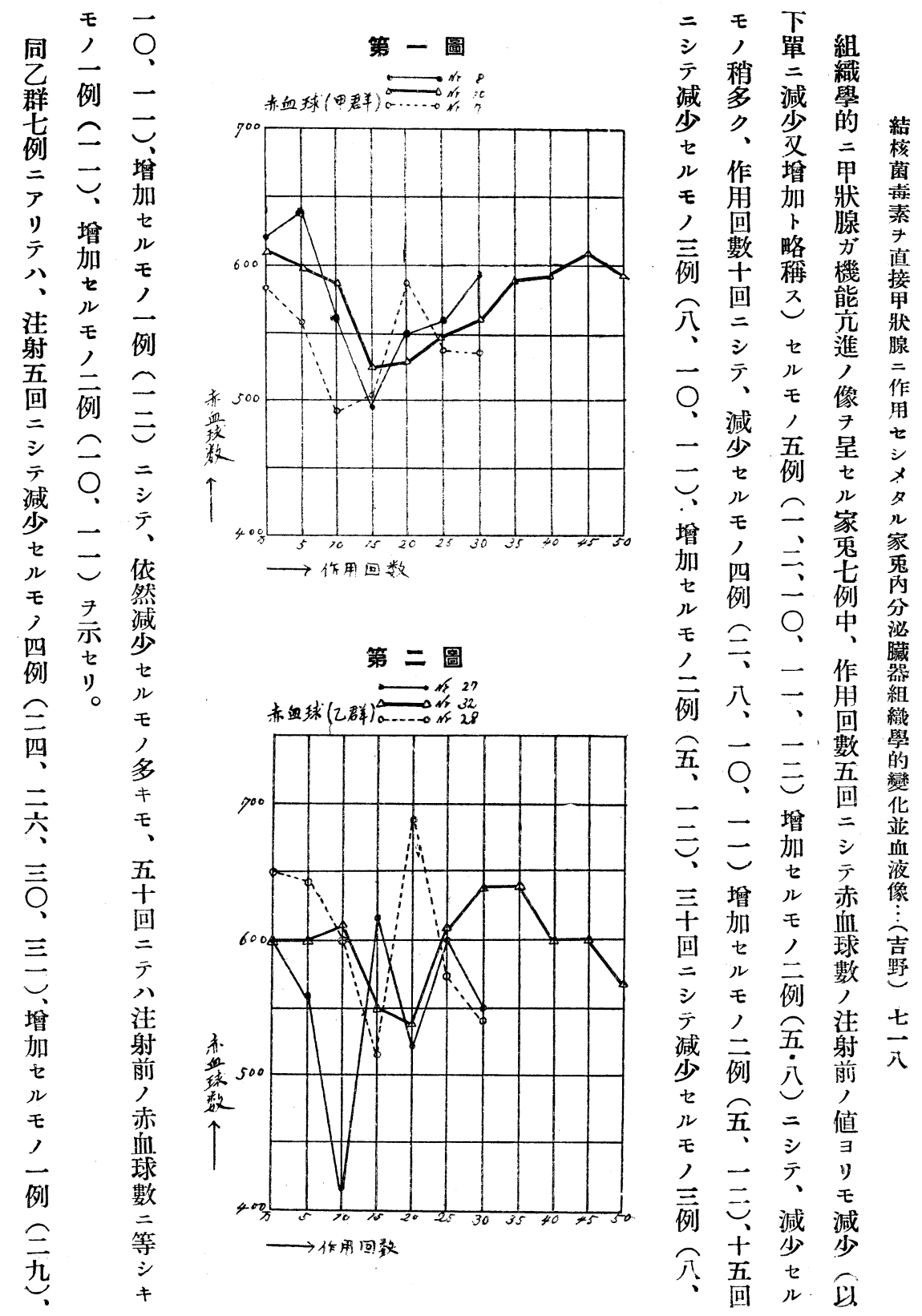


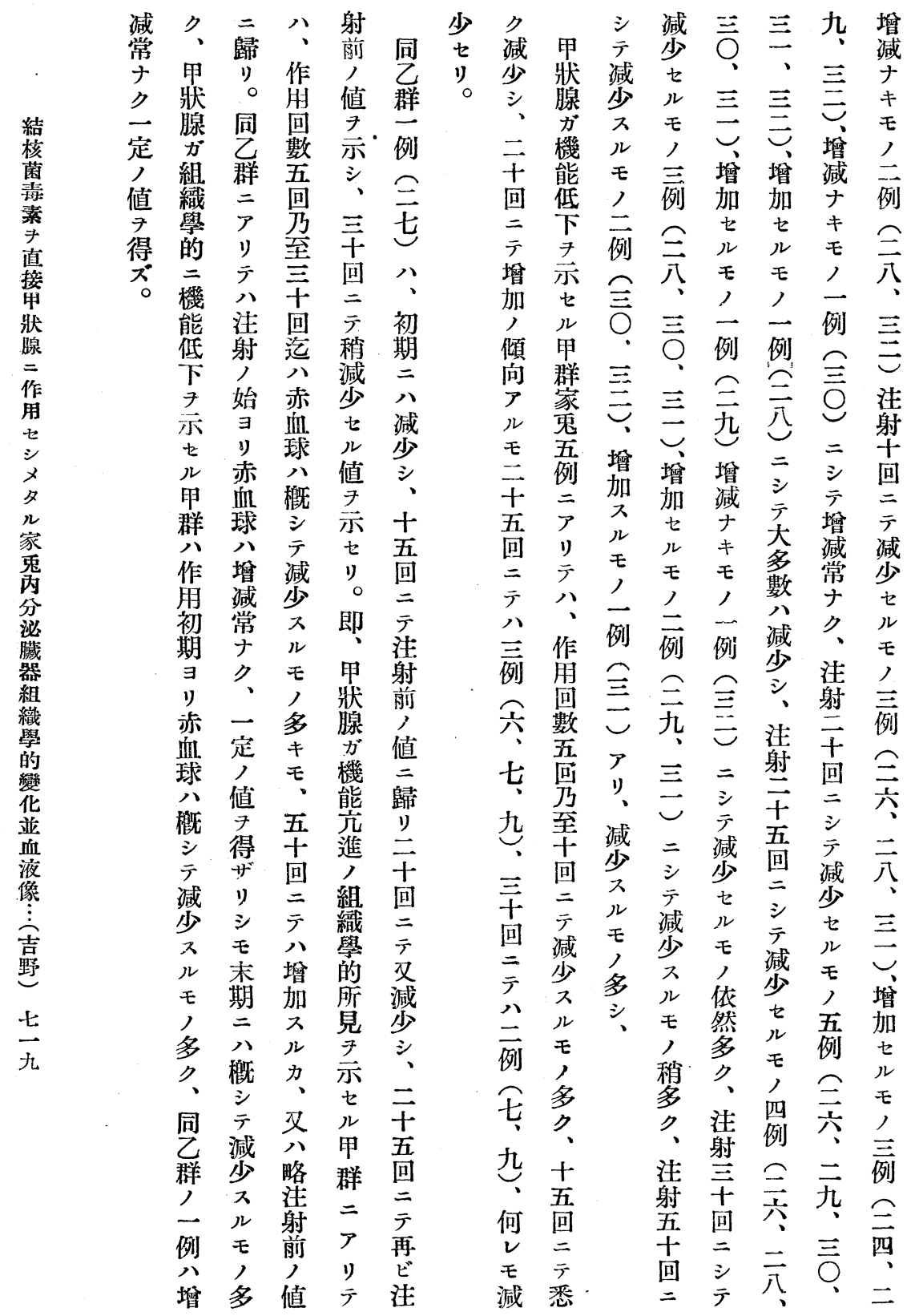




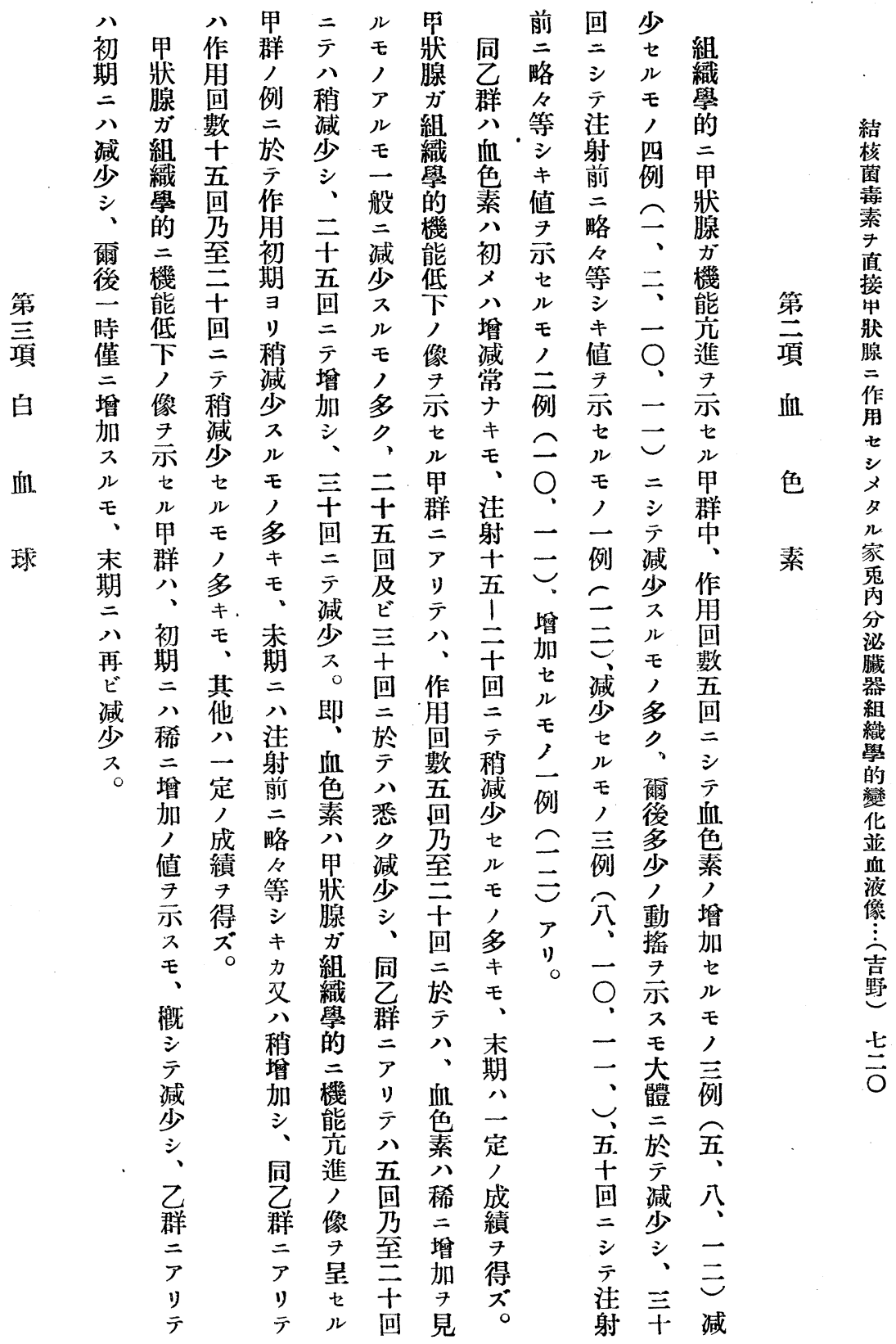




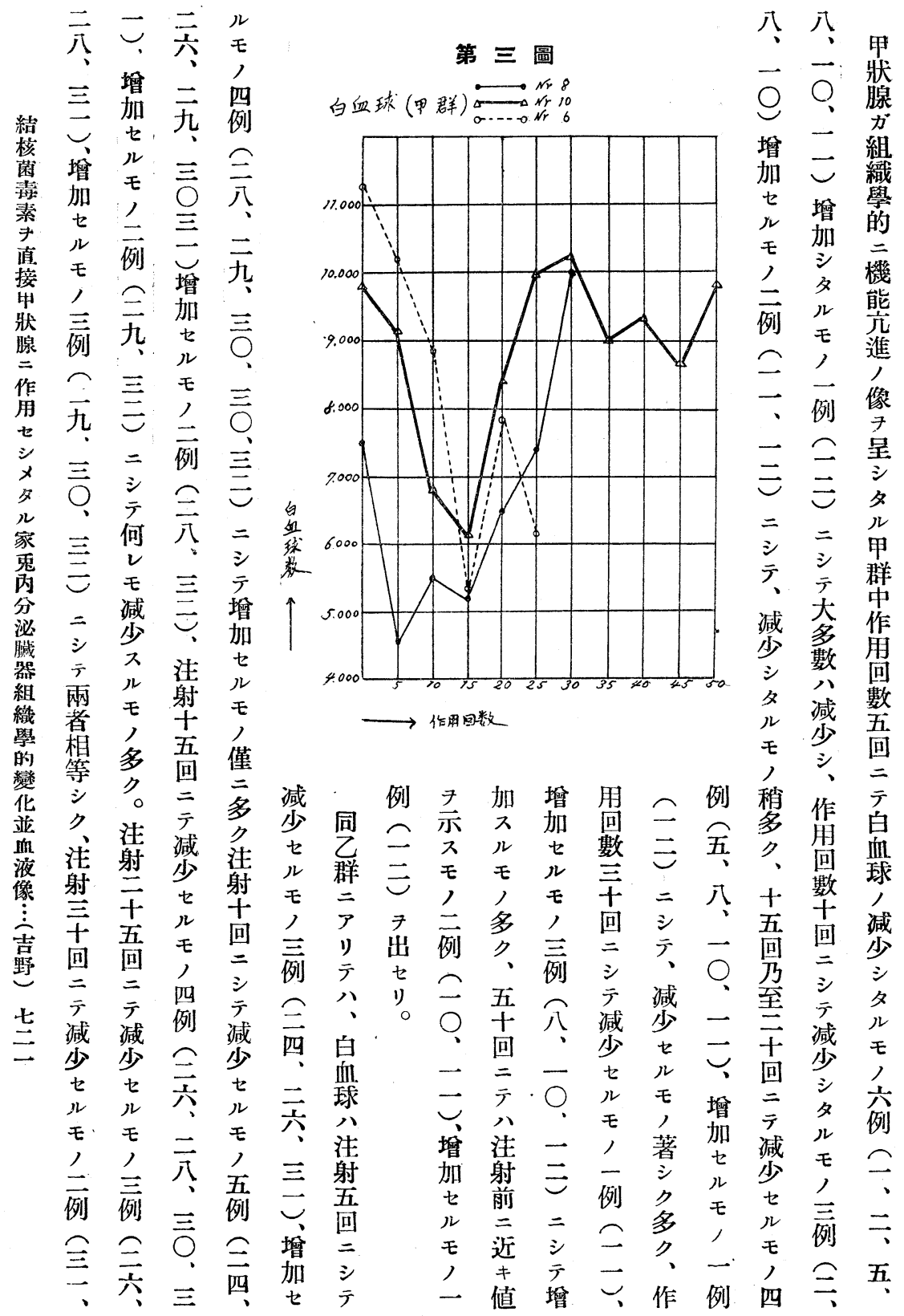




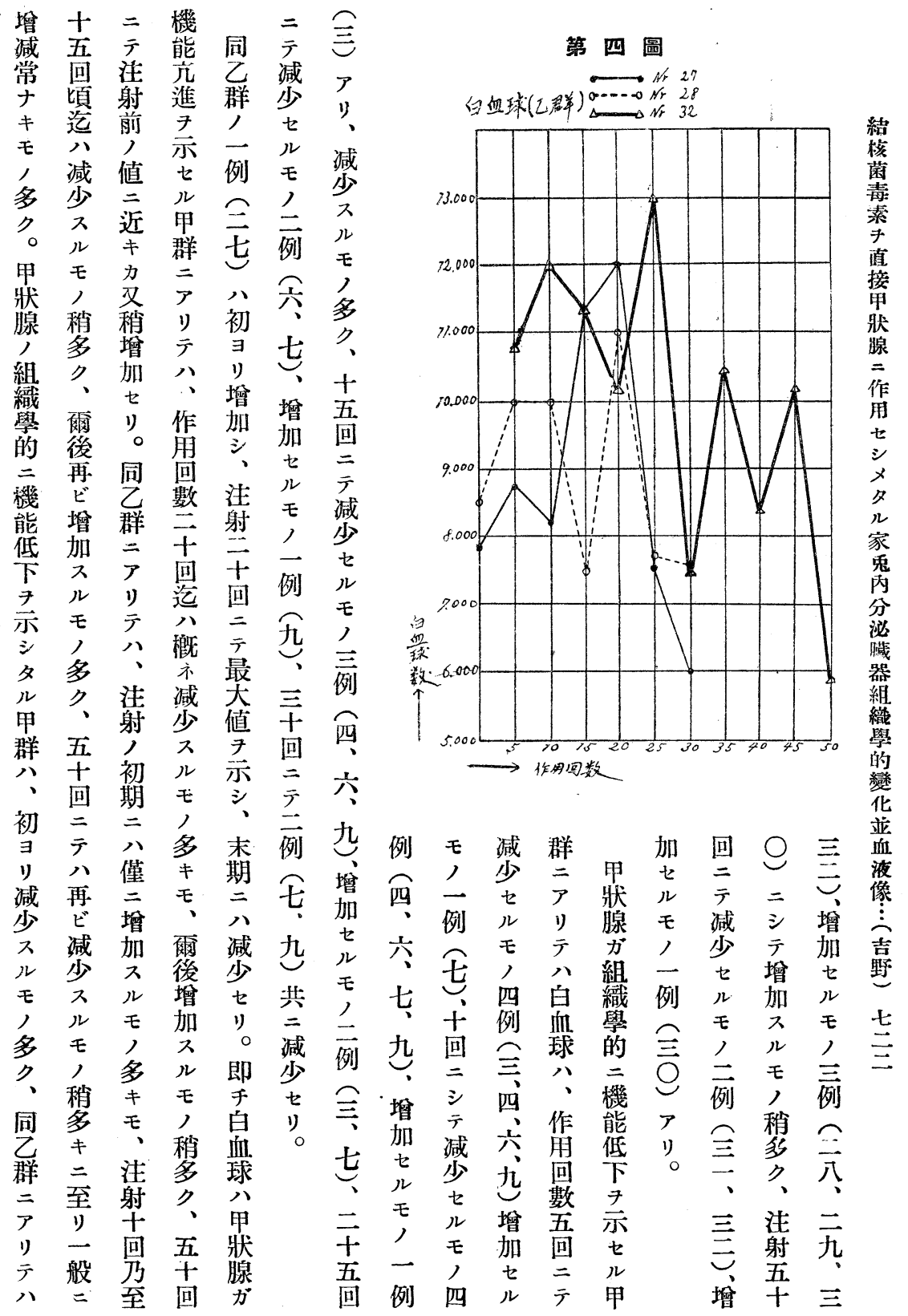




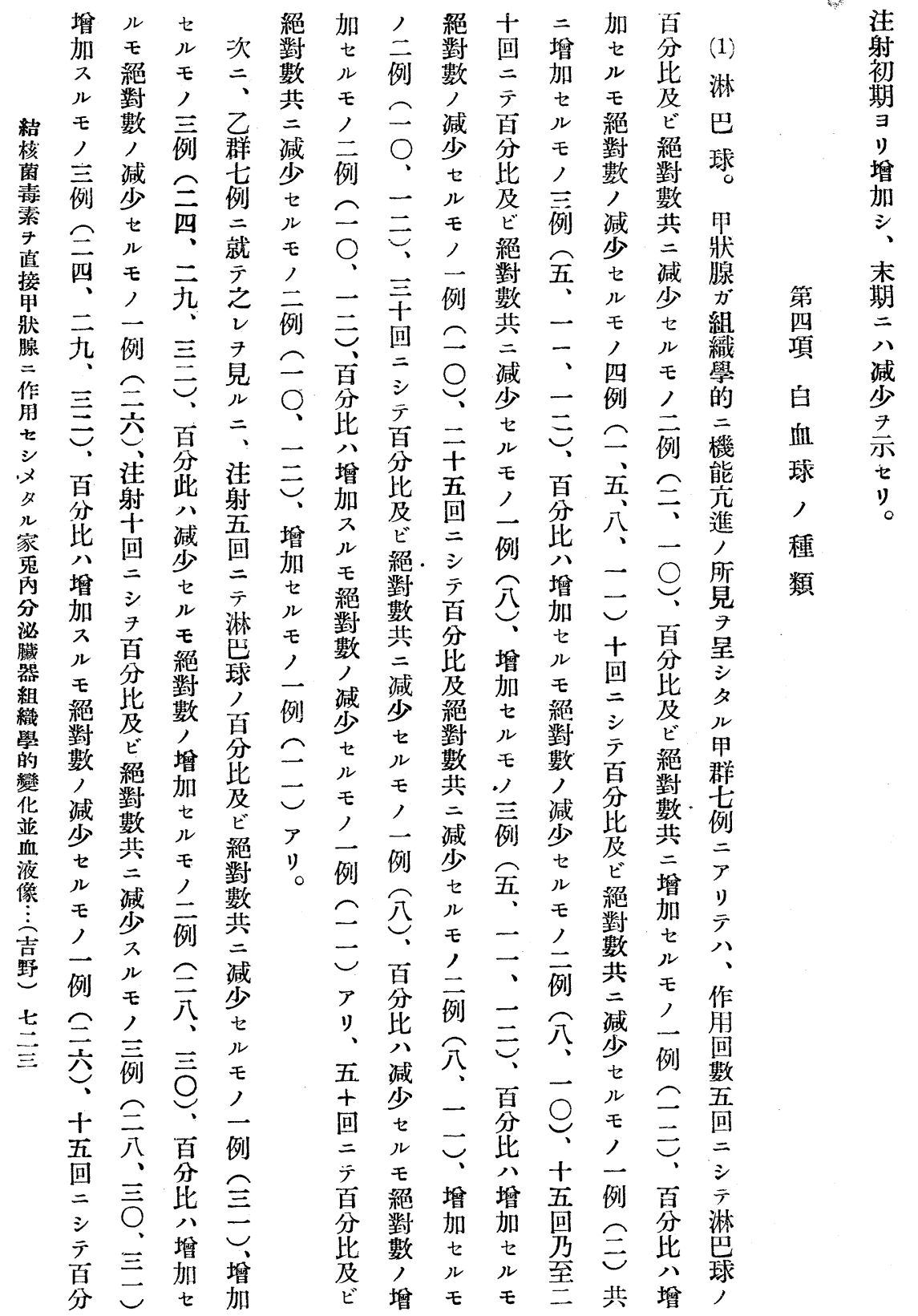




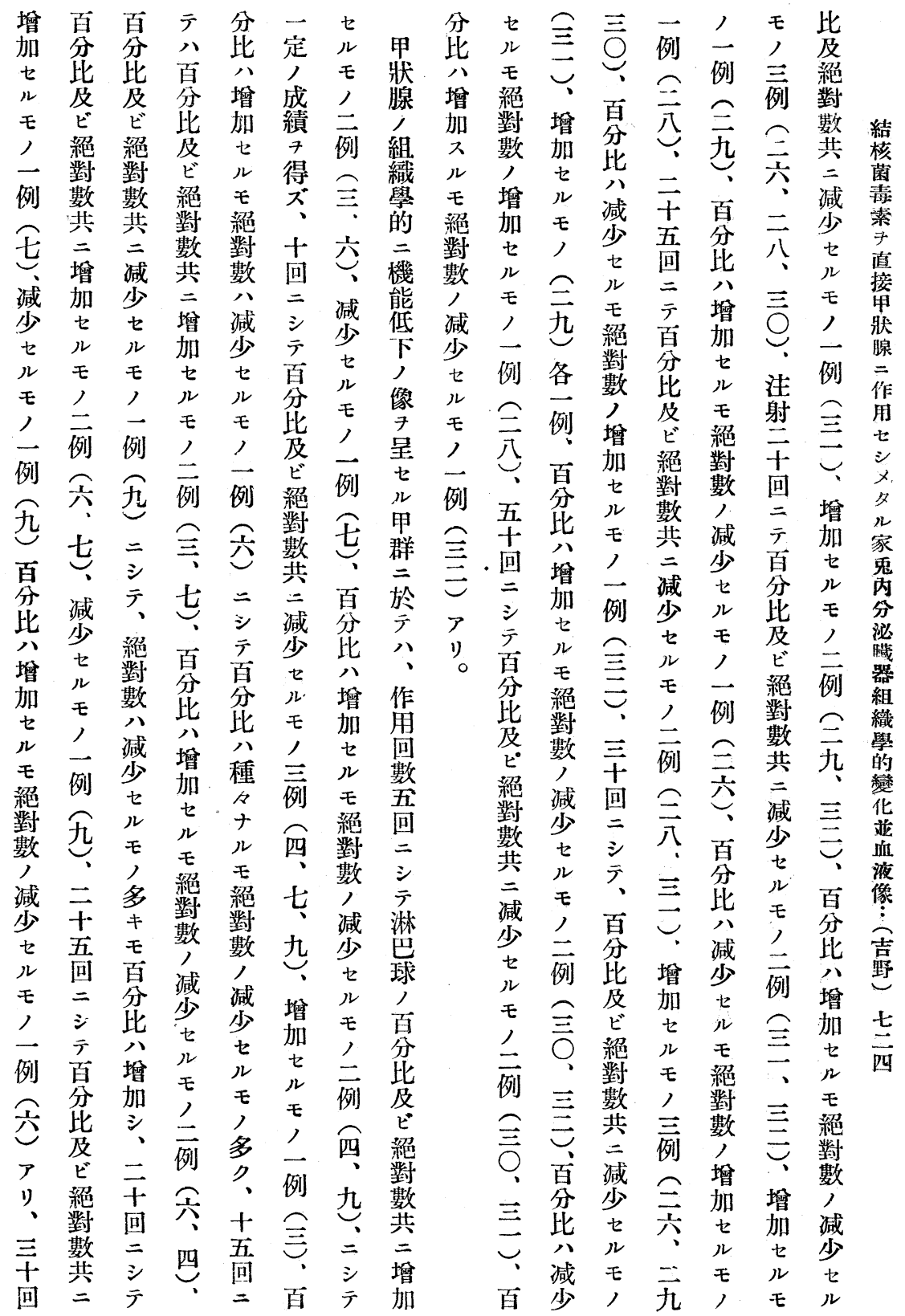




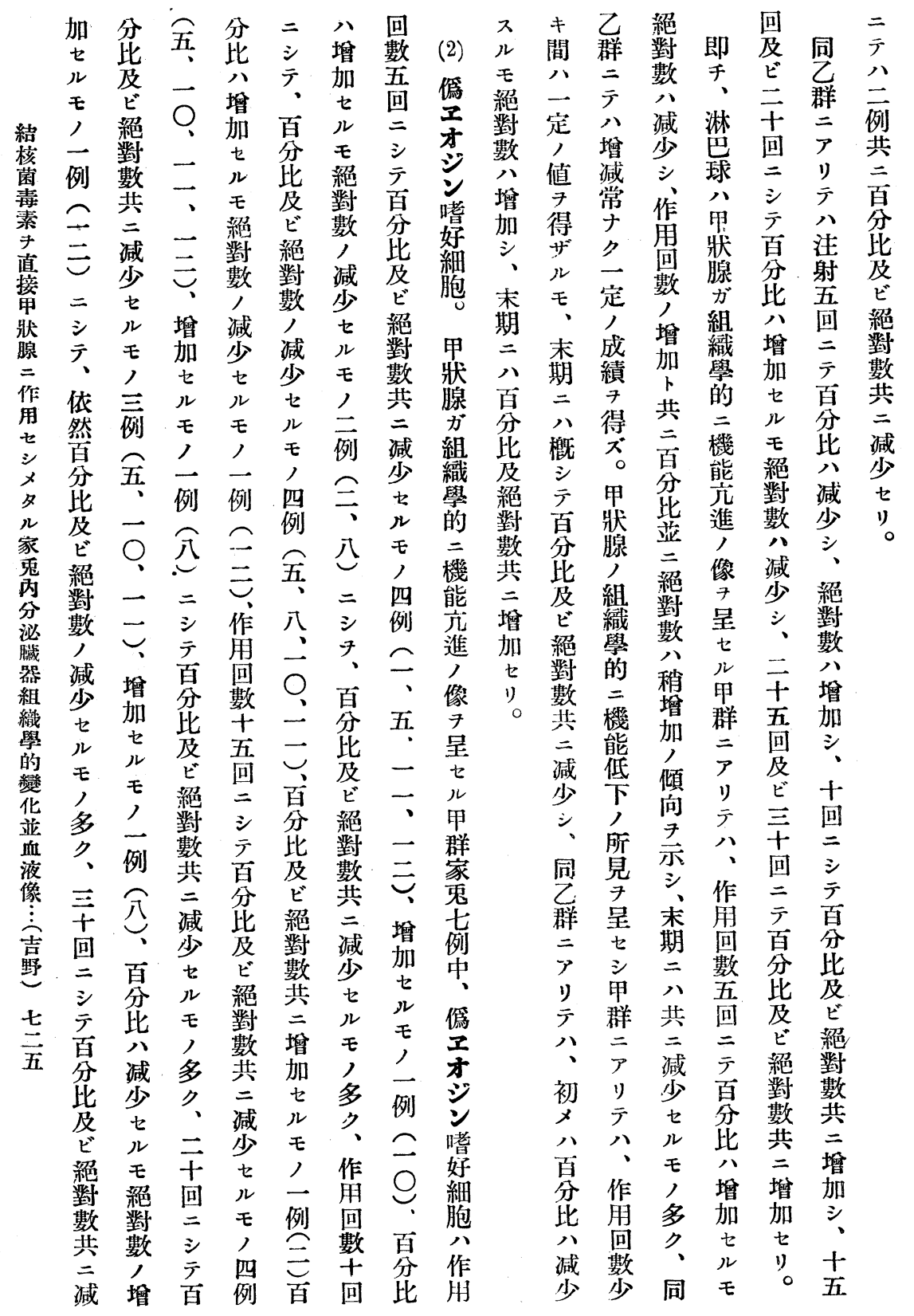




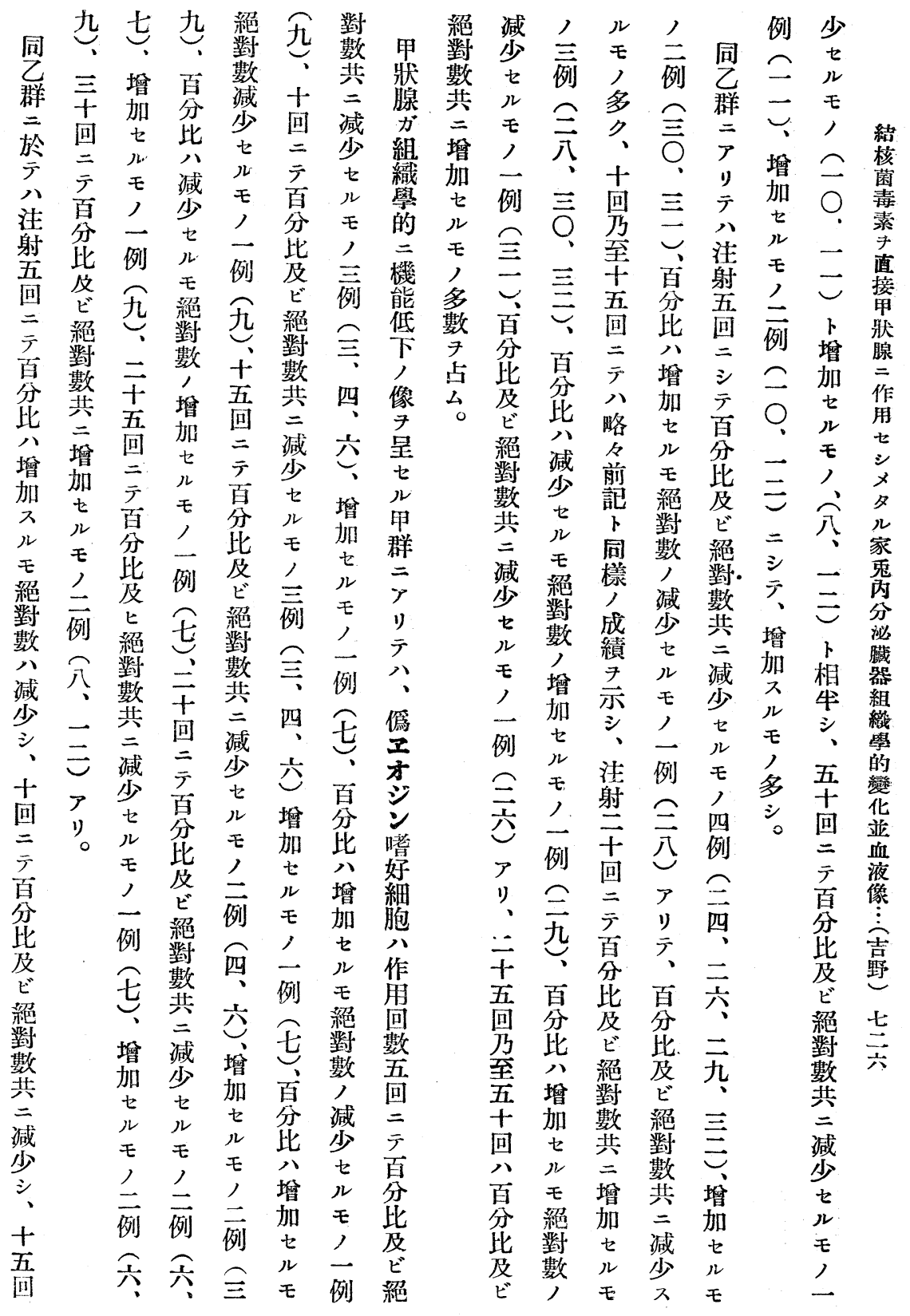




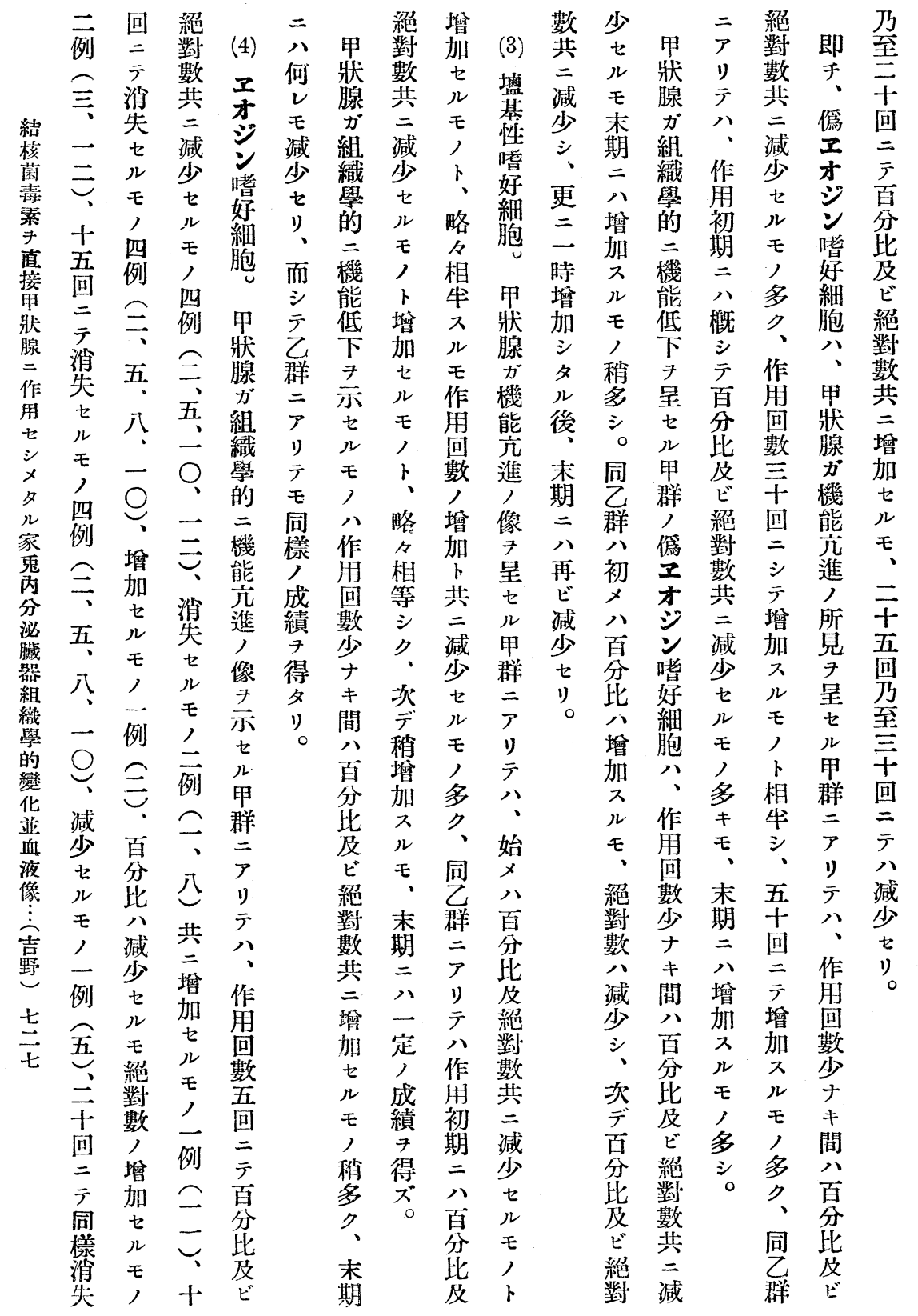




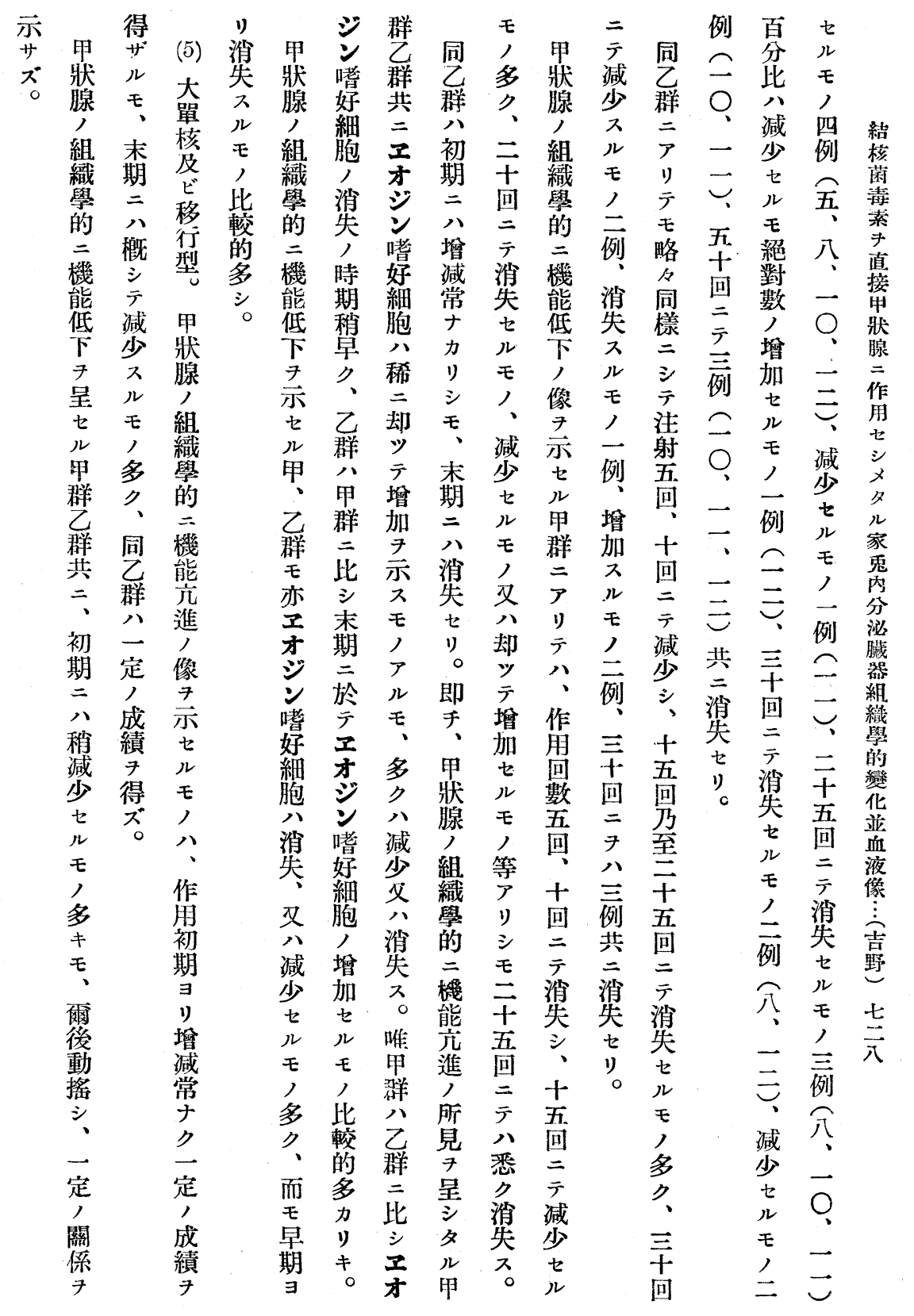




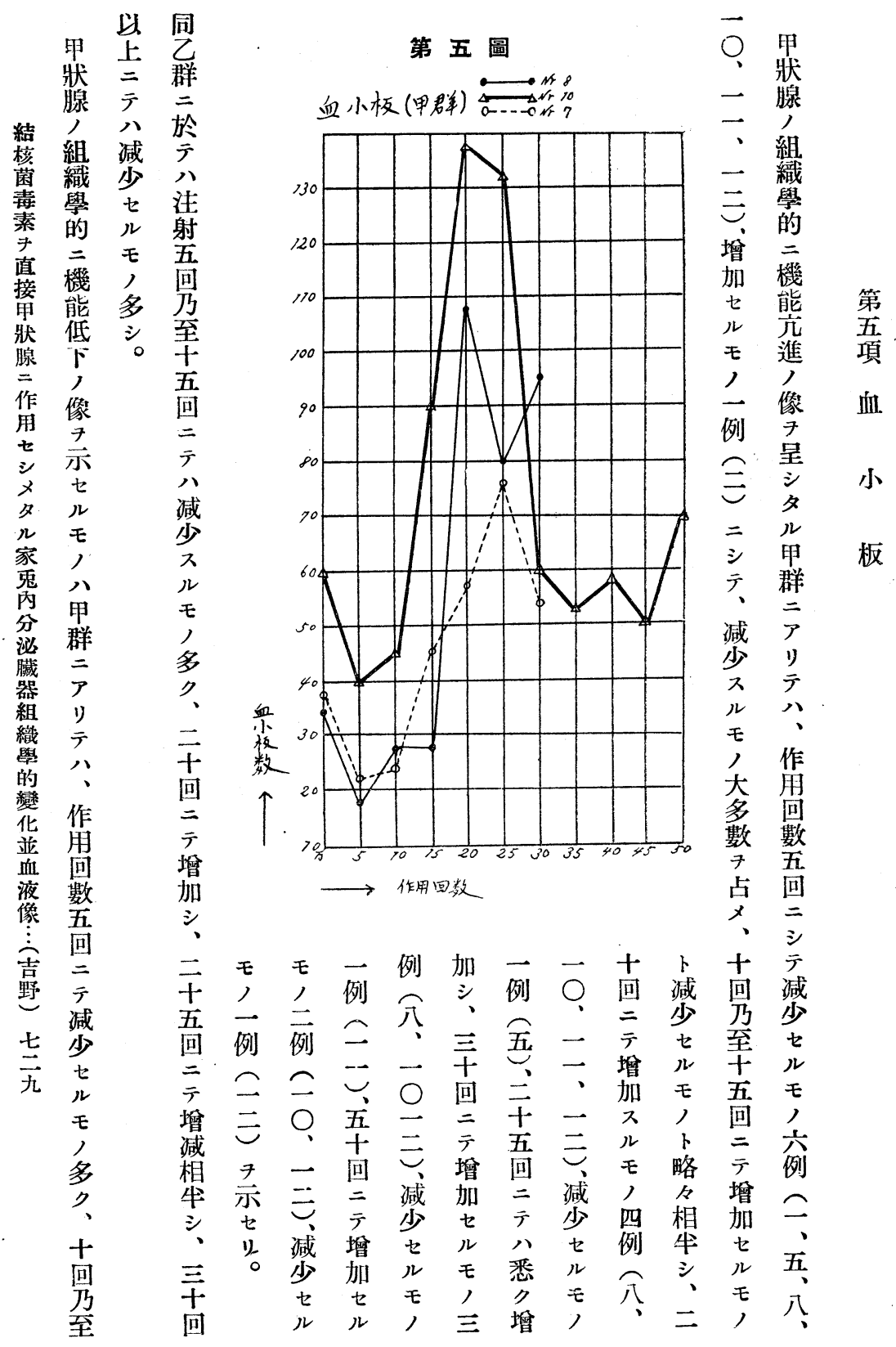




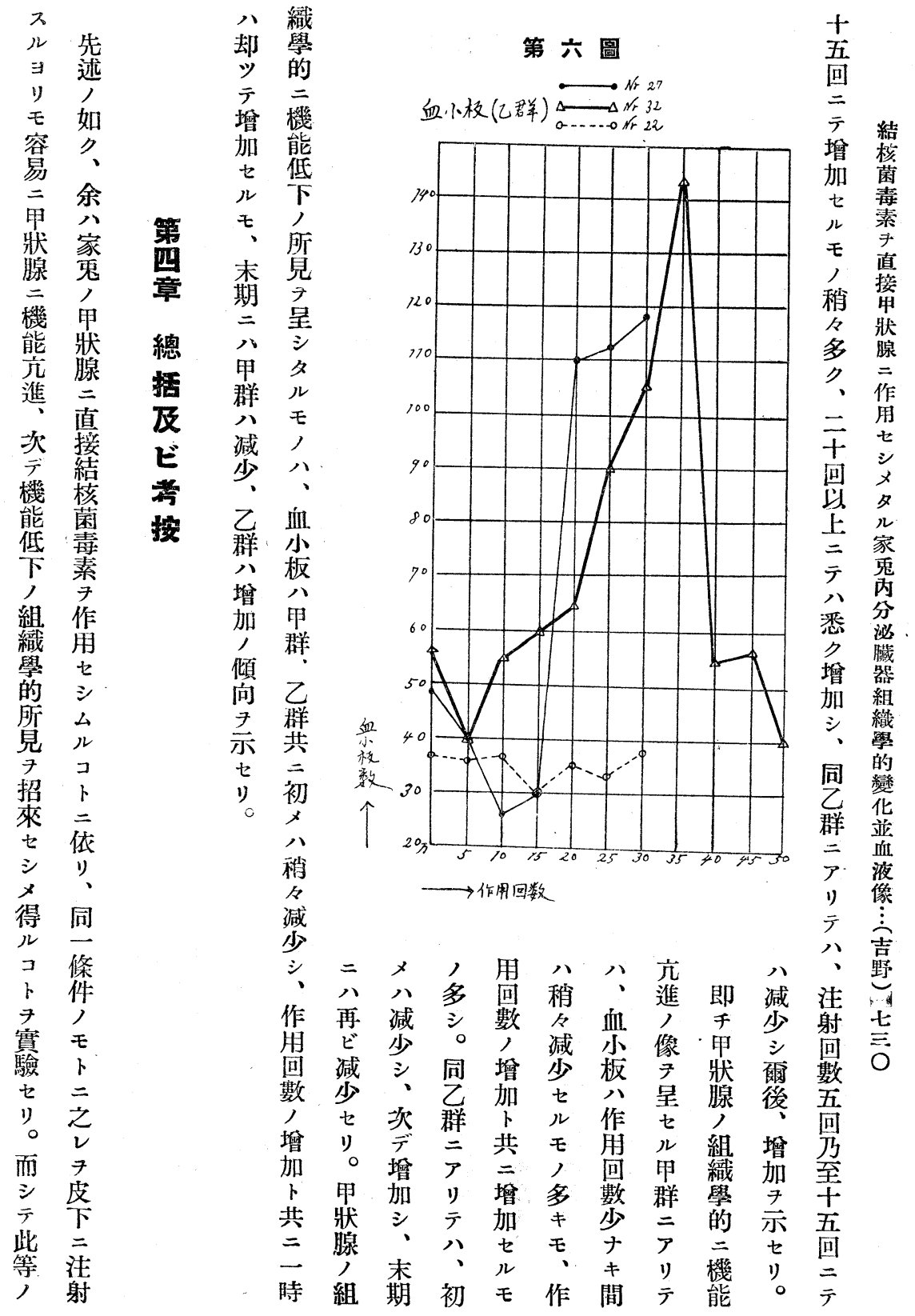




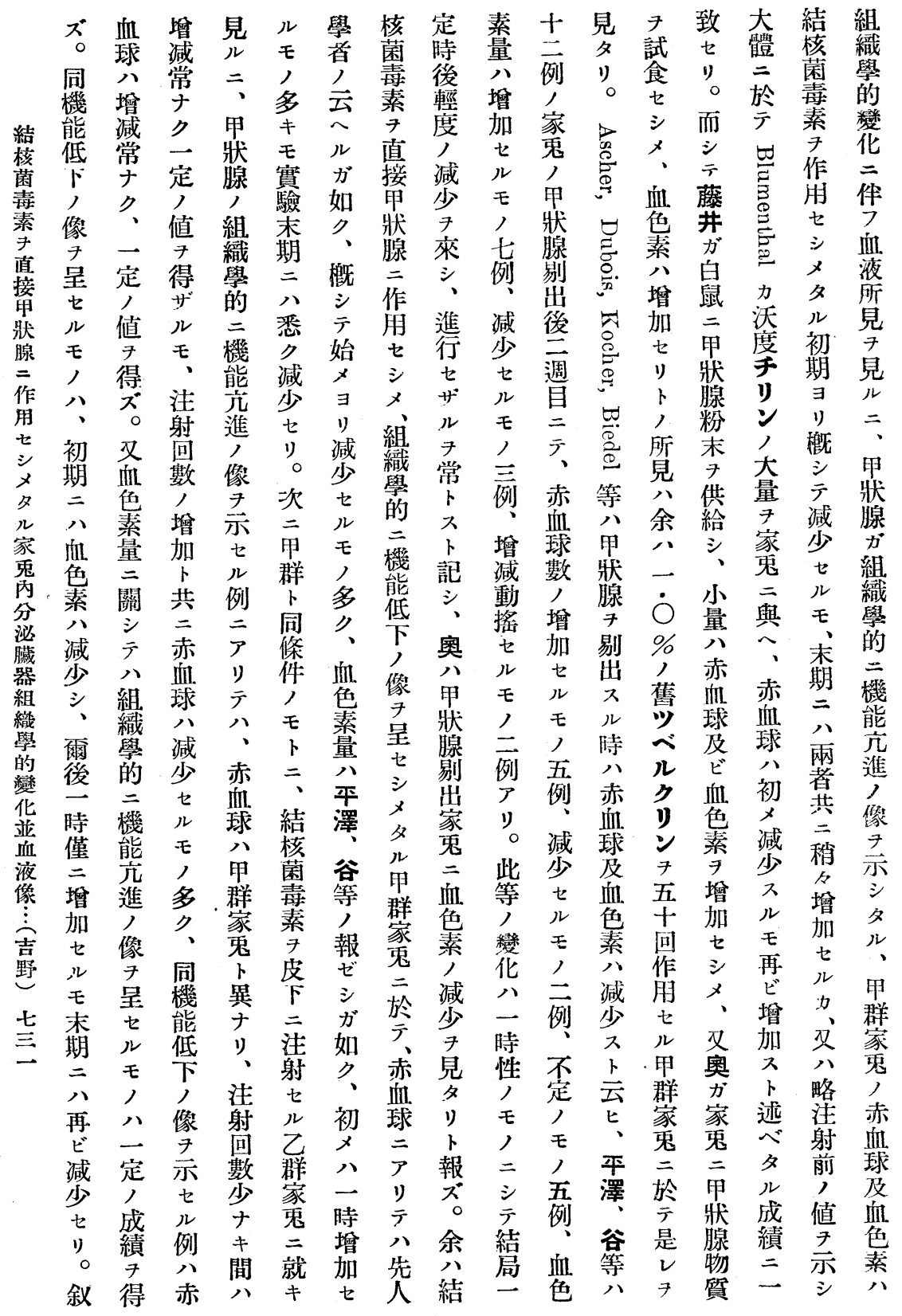




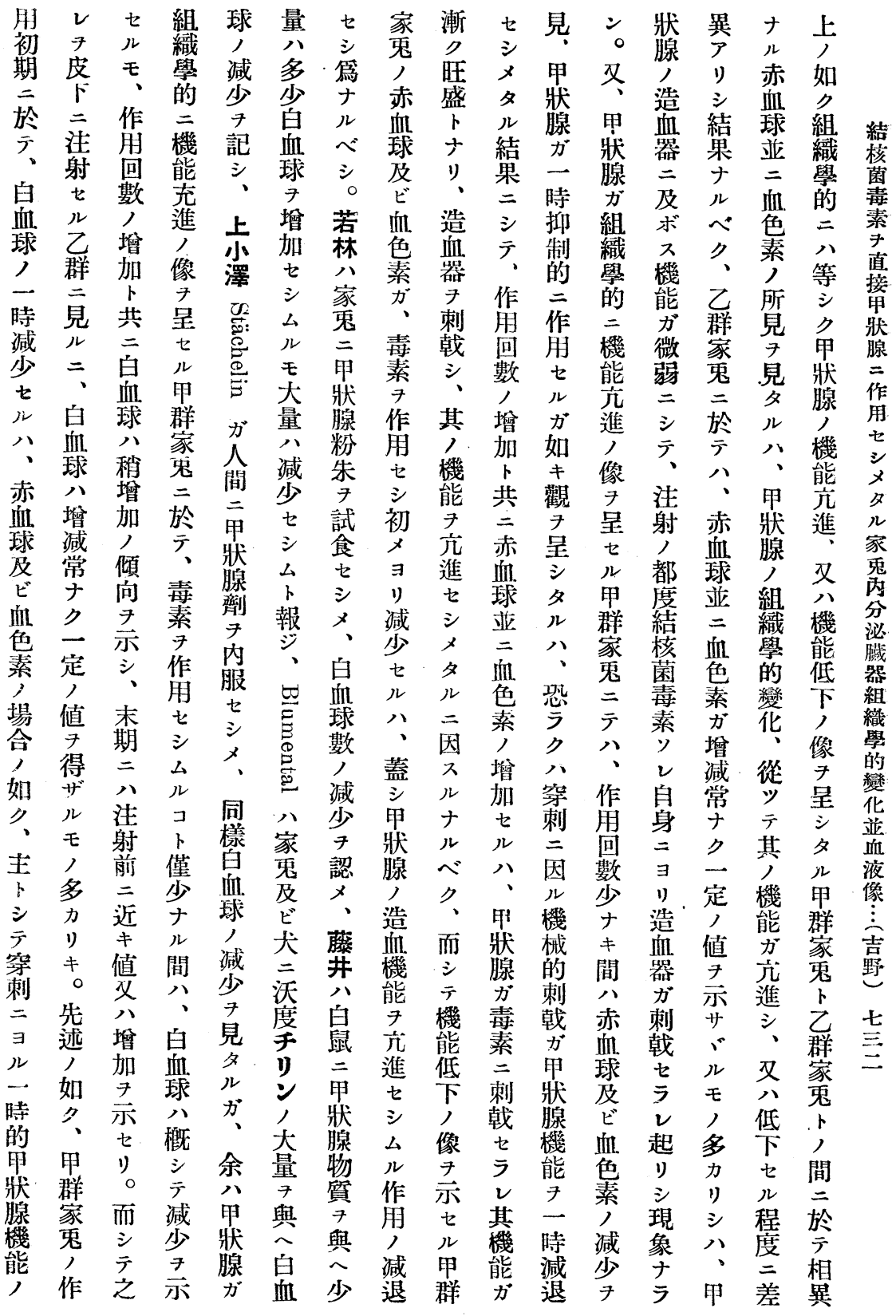




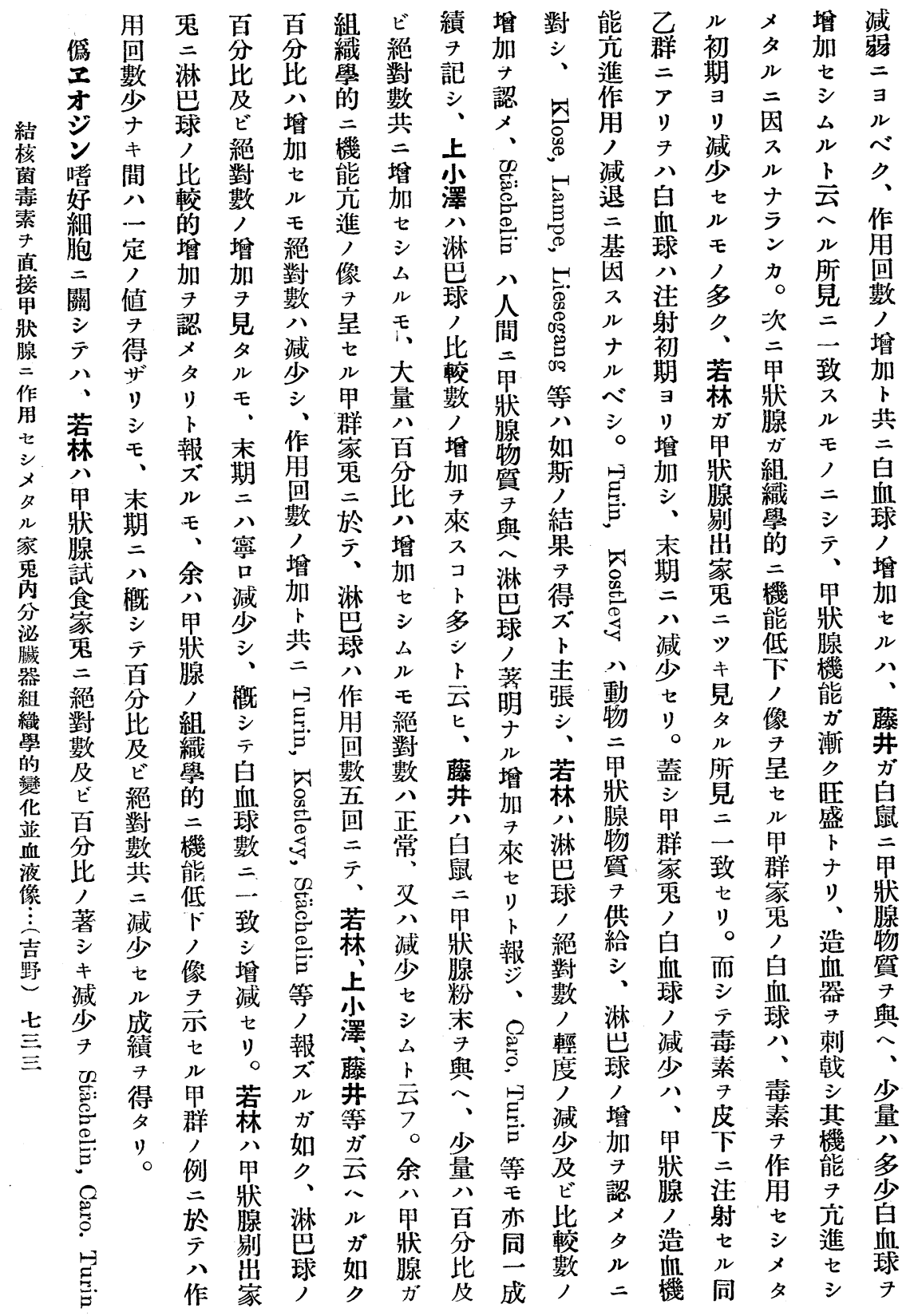




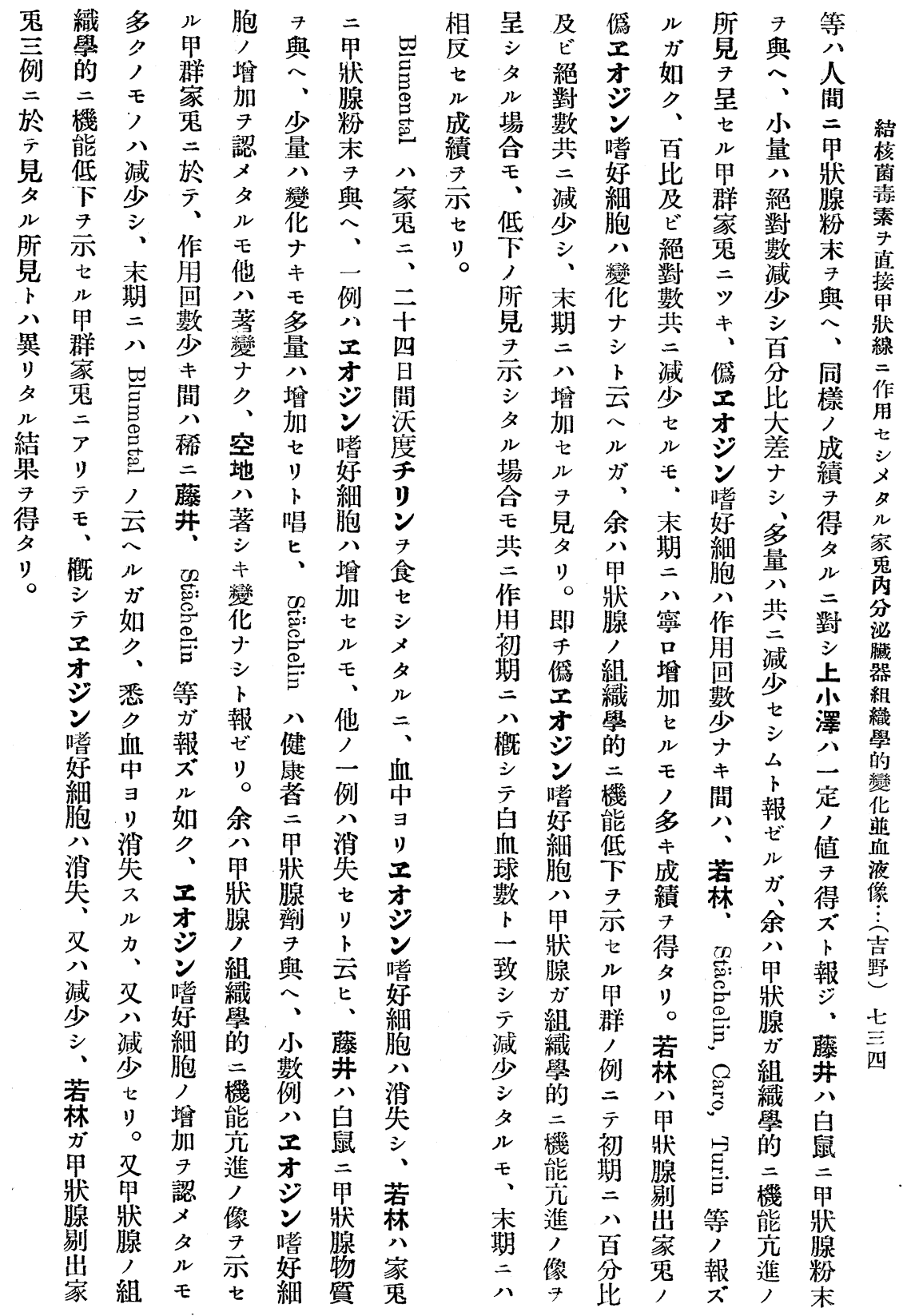




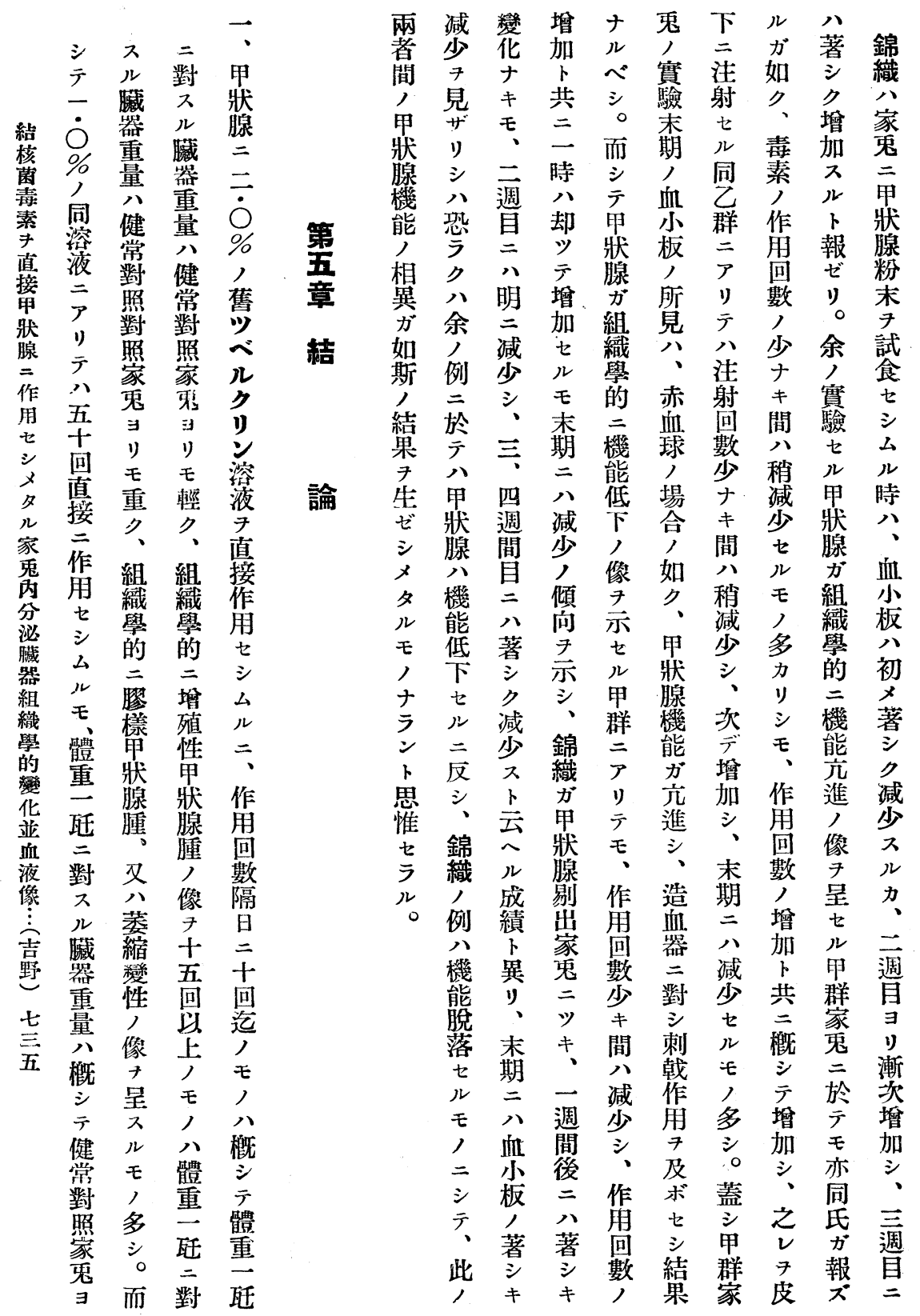




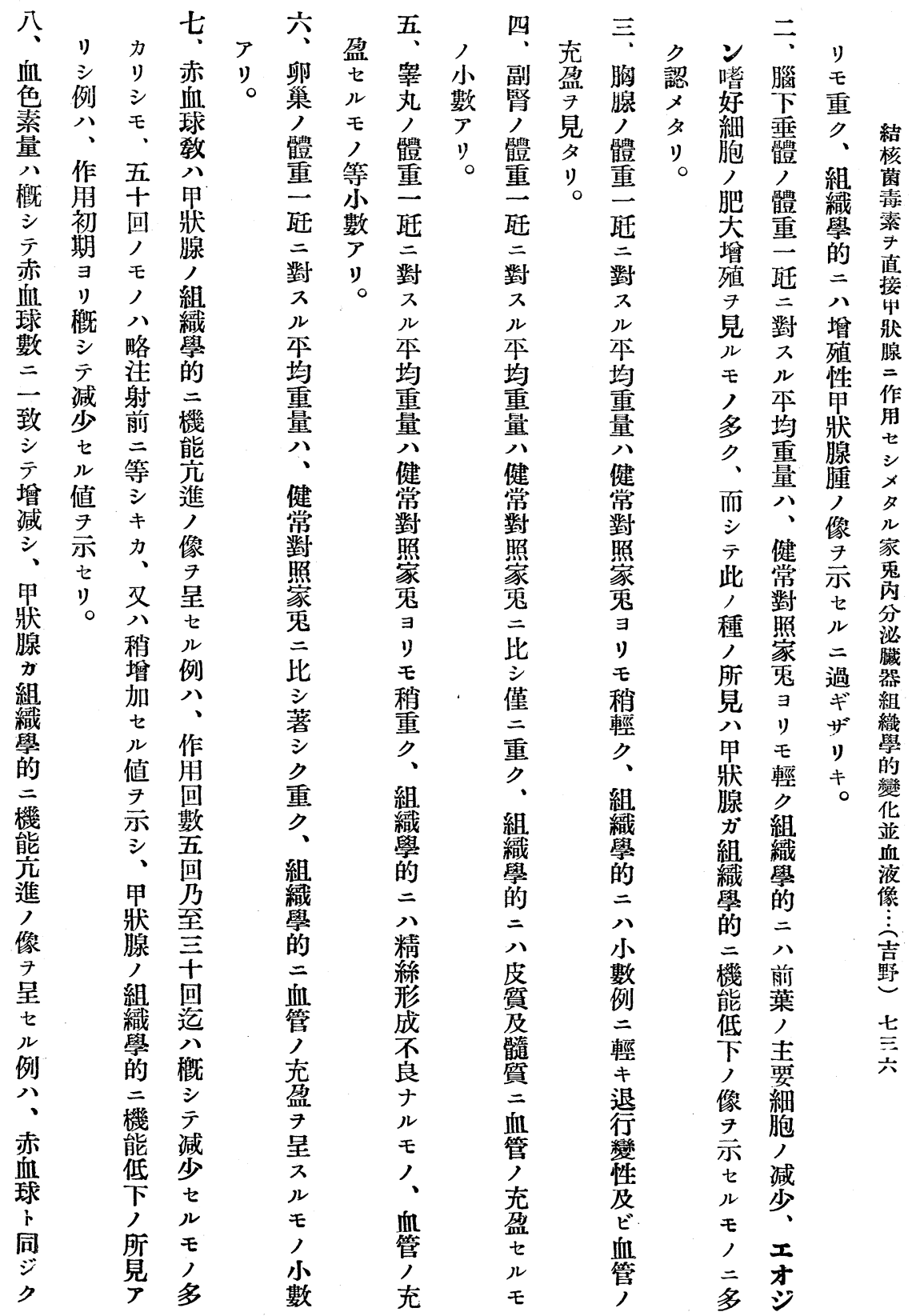




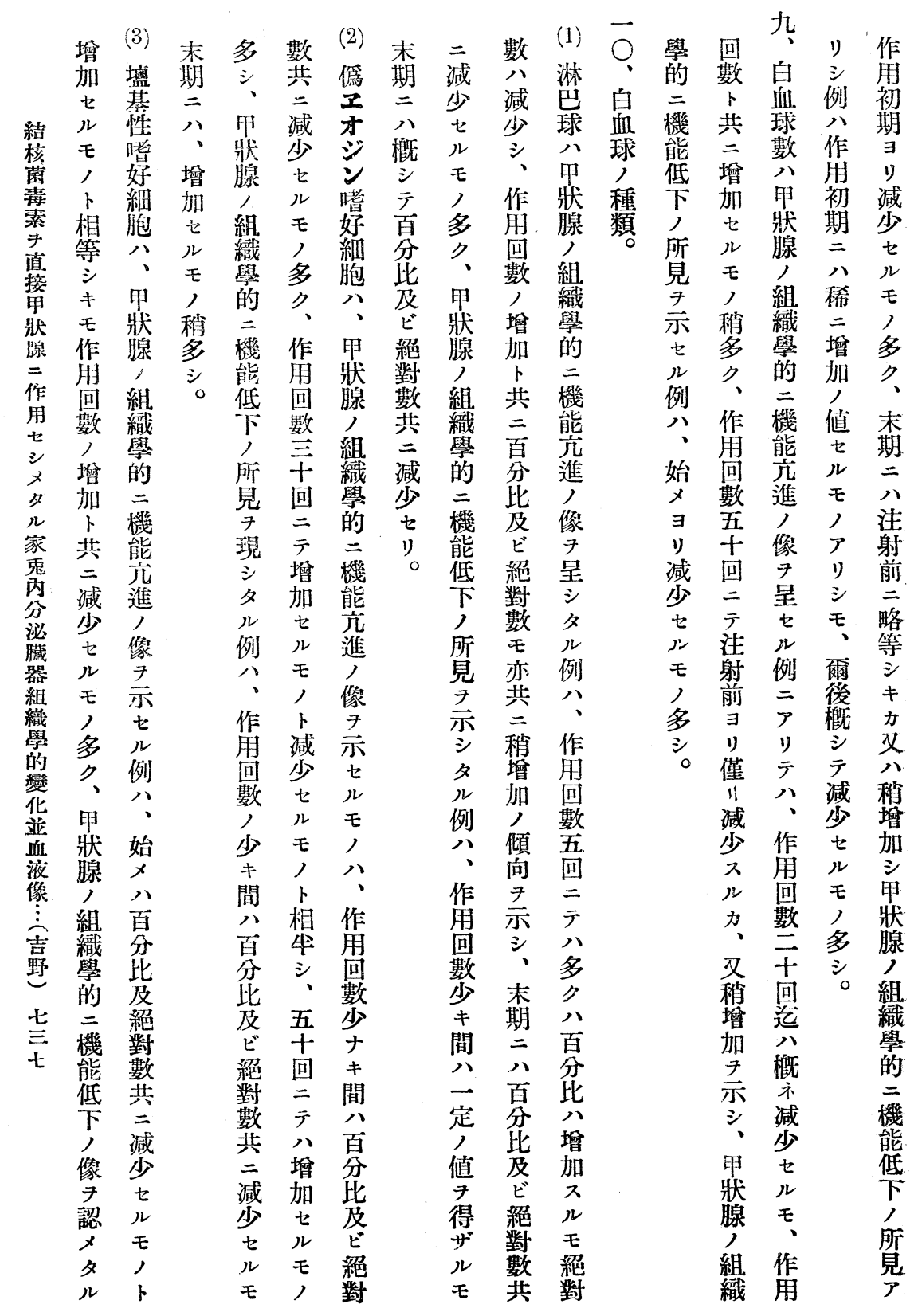



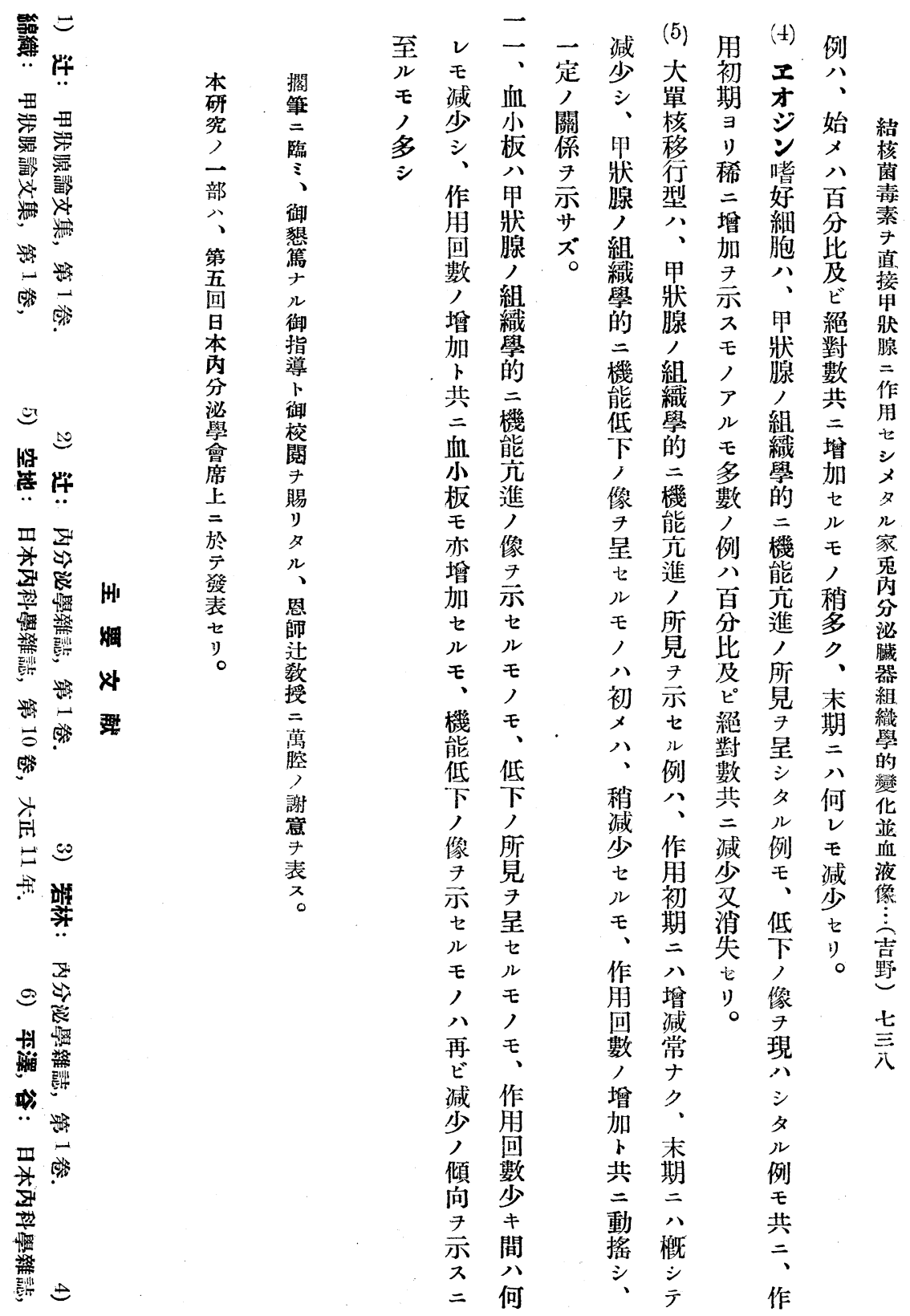


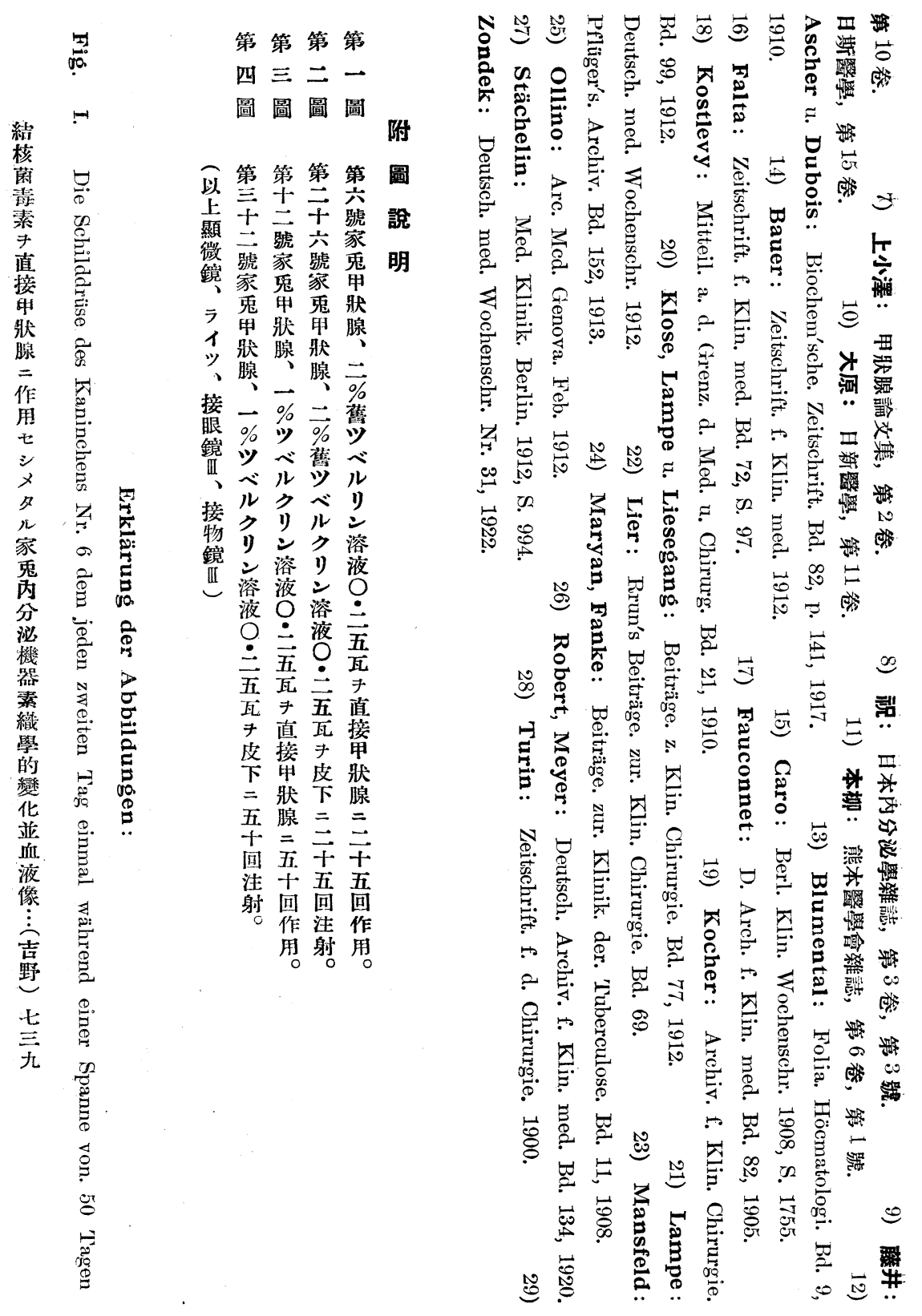




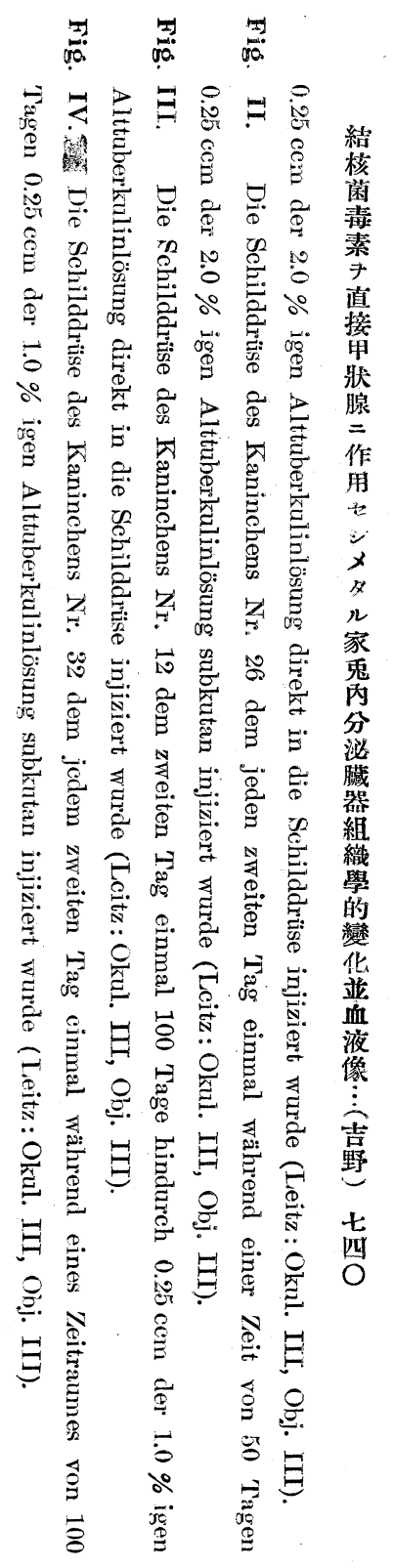


吉野論文附圖

Fig. I

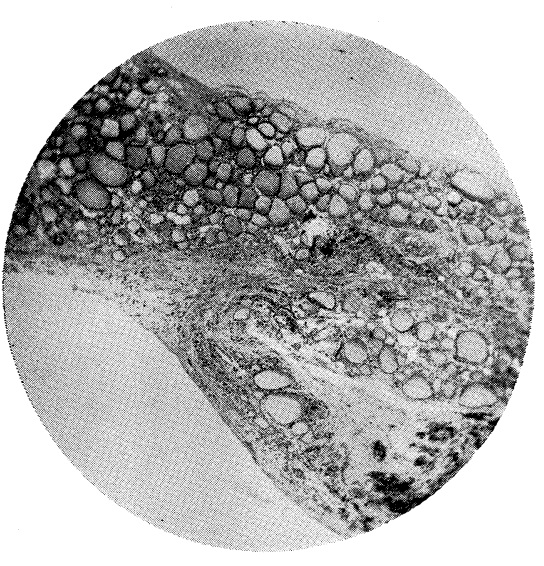

Fig. III

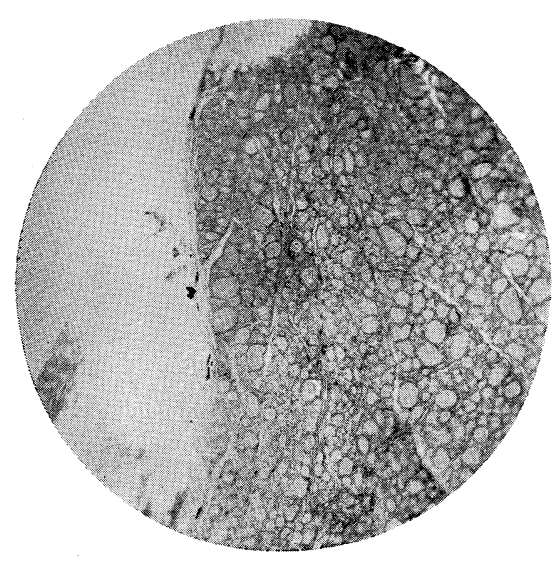

Fig. II

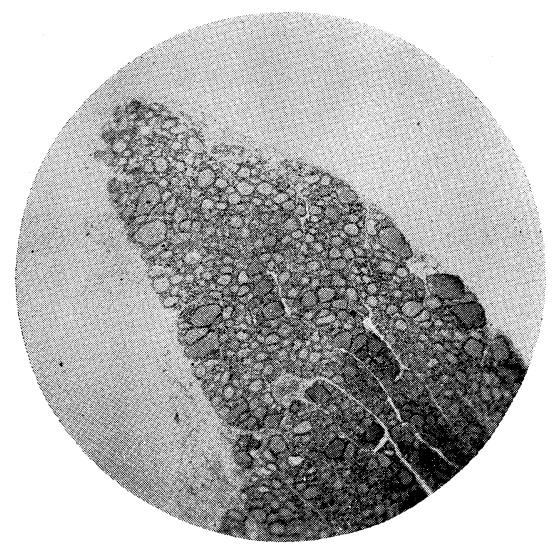

Fig. IV

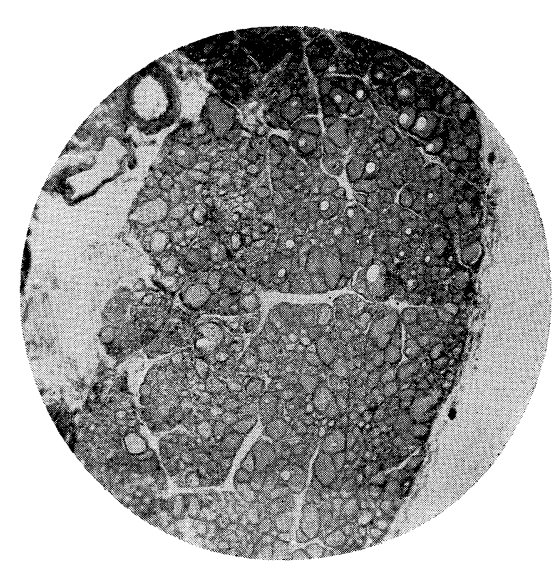




\title{
Studien über den Einfluss der verschiedenen inner- sekretorischen Drüsen auf den Gaswechsel der B-avitaminösen Tiere. V. Mitteilung. Ueber den Einfluss der Hoden.
}

\author{
Von
}

Dr. S. Shinobe.

(Aus der I. med. Klinik der Kaiserl. Univers, zu Kyoto, Japan. Direktor: Prof. Dr. K. Tsuji.)

Der Verfasser stellte dieses Experiment an gesunden männlichen weissen Ratten an, um die Wirkung der Hodensubstanz auf den Gaswechsel bei gesunden Tieren und bei B-avitaminösen Tieren festzustellen. Der Gaswechsel wurde nach der modifizierten FosterSundstroemschen Methode bestimmt.

Die Resultate sind die folgenden :

1) Wenn man die Ratten mit getrocknetem Hodenpulver füttert, so zeigt der Sauerstoffverbrauch Neigung zu einer leichten Steigerung.

2) Wenn man die Ratten mit vitaminfreier Kost und mit getrocknetem Hodenpulver füttert, so wird die Herabsetzung des Sauerstoffverbrauches durch Avitaminose verstärkt (Autoreferat)

\section{Das histologische Bild der innersekretorischen}

\section{Organe und das Blutbild von Kaninchen,denen}

Alttuberkulin direkt durch die Haut in die Schilddrüse injiziert wurde.

$$
\text { Von }
$$

Dr. S. Yoshino.

(Aus der I. med. Klinik der Kaiserlichen Universität zu Kyoto, Japan. Direktor : Prof. Dr. K. Tsuji.) 
Bei einem Kaninchen, welchem jeden zweiten Tag einmal 0.25 com 1.0 bis $2.0 \%$ iger Alttuberkulinlösung direkt durch die Haut in die Schilddrüse injiziert worden war, wurde jeden zehnten Tag das Blutbild und nach 10 bis 100 Tagen das histologische Bild der innersekretorischen Organe untersucht.

Die Resultate waren die folgenden :

1) Die Schilddrüse zeigte bei 5-bis 10 -mal mit $2 \%$ iger Alttuberkulinlösung injizierten Fällen meist Gewichtsabnahme und das Bild des parenchymatösen Hyperthyreoidifmus, dagegen bei Fällen, denen 15-bis 30-mal dieselbe Lösung injiziert worden war, Gewichtszunahme und das Bild des Kolloidstrumas. Bei 50-mal mit $1 \%$ iger Alttuberkulinlösung injizierten Fällen nahm das Thyreoideagewicht zu und ergab sich das Bild des parenchymatösen Hyperthyreoidismus.

2) Die Hypophysis wies in meisten Fällen Gewichtsabnahme auf. In den Vorderlappen waren die Hauptzellen vermindert und die eosinophilen Zellen vergrössert und vermehrt.

3) Die Thymusdrüse nahm an Gewicht etwas ab und liess nur bei einigen Fällen geringgradige regressive Veränderungen erkennen.

4) Bei der Nebenniere und der Geschlechtsdrüse hatte das Gewicht zugenommen und waren histologisch keine nennenswerten Veränderungen zu konstatieren.

5) Die Erythrocytenzahl war bei der A-Gruppe (d. i. diejenige, die histologisch das Hyperfunktionsbild der Schilddrüse aufwies) im Anfangsstadium meist vermindert und im Endstadium etwas vermehrt, dagegen bei der B-Gruppe (d. i, diejenige, die histologisch das Hypofunktionsbild der Schilddrüse aufwies) von Anfang an im allgemeinen vermindert.

6) Der Hämoglobingehalt und die Erythrocytenzahl schwankten fast immer parallel.

7) Die Leukocytenzahl zeigte bei der A-Gruppe anfangs meist eine Abnahme und später eine geringgradige Zunahme, während sie bei der B-Gruppe von Anfang an in den meisten Fällen vermindert war. 
8) Die Zellarten der Leukocyten :

(1) Die Lymphocyten waren bei der A-Gruppe anfangs relativ. vermehrt und absolut vermindert, aber später relativ und absolut vermehrt. Bei der B-Gruppe zeigten die Lymphocyten anfangs keine nennenswerten Veränderungen, später aber relative und absolute Abnahme.

(2) Die polynukleären pseudoeosinophilen Leukocyten waren bei der A-Gruppe anfangs meist relativ und absolut vermindert, aber später vermehrt. Bei der B-Gruppe zeigte sie die gleichen Resultate wie die A-Gruppe.

(3) Die polynukleären eosinophilen Leukocyten waren bei der A-und B-Gruppe von Anfang an in den meisten Fällen relativ und absolut vermindert.

(4) Die polynukleären basophilen Leukocyten und Monocyten zeigten keine nennenswerten Veränderungen.

9) Die Zahl der Blutplättchen war bei der A-sowie B-Gruppe anfangs vermindert und dann etwas vermehrt, aber verminderte sich bald darauf nur bei der B-Gruppe.

(Autoreferat)

\title{
Ueber den Jodstoffwechsel von Kaninchen, denen Alttuberkulin und verschiedene Vaccine direkt durch die Haut in die Schilddrüse injiziert wurden.
}

$$
\text { Von }
$$

\author{
Dr. S. Yoshino.
}

(Aus der I. med. Klinik der Kaiserlichen Universität zu Kyoto, Japan. Direktor: Prof. Dr. K. Tsuji.)

Der Verfasser injizierte den Kaninchen wiederholt jeden zweiten Tag einmal direkt durch die Haut in die Schilddrüse $0.25 \mathrm{ccm}$ Alttuberkulin (3\%) und verschiedene Vaccine, nämlich Gonokokken-, 